\title{
SI JUDY ANN SANTOS AT ANG WIKA NG TELESERYE
}

\author{
Louie Jon A. Sánchez \\ Ateneo de Manila University \\ Isanchez@ateneo.edu
}

\begin{abstract}
The actress Judy Ann Santos boasts of an illustrious and sterling career in Philippine show business, and is widely considered the "queen" of the teleserye, the Filipino soap opera. In the manner of Barthes, this paper explores this queenship, so-called, by way of traversing through Santos' acting history, which may be read as having founded the language, the grammar of the said televisual dramatic genre. The paper will focus, primarily, on her oeuvre of soap operas, and would consequently delve into her other interventions in film, illustrating not only how her career was shaped by the dramatic genre, pre- and postEDSA Revolution, but also how she actually interrogated and negotiated with what may be deemed demarcations of her own formulation of the genre. In the end, the paper seeks to carry out the task of generically explicating the teleserye by way of Santos's oeuvre, establishing a sort of authorship through intermedium perpetration, as well as responding on her own so-called "anxiety of influence" with the esteemed actress Nora Aunor.
\end{abstract}

\section{Keywords}

aura; iconology; ordinariness; rules of assemblage; teleseries

\begin{abstract}
About the Author
Louie Jon A. Sánchez is the author of two poetry collections in Filipino, At Sa Tahanan ng Alabok (Manila: U of Santo Tomas Publishing House, 2010), a finalist in the Madrigal Gonzales Prize for Best First Book, and Kung Saan sa Katawan (Manila: U of Santo Tomas Publishing House, 2013), a finalist in the National Book Awards Best Poetry Book in Filipino category; and a book of creative nonfiction, Pagkahaba-haba Man ng Prusisyon: Mga Pagtatapat at Pahayag ng Pananampalataya (Quezon City: U of the Philippines P, forthcoming). He teaches literature, writing, and popular culture at the Department of English, Ateneo de Manila University. He also co-directs the Annual Poetry in Filipino Workshop of the Linangan sa Imahen, Retorika, at Anyo (LIRA). He holds the distinction of being awarded "Makata ng Taon" (Poet of the Year) thrice, in 2006, 2009, and 2011, at the Talaang Ginto (Golden List) poetry contest of the Philippine Government's Komisyon
\end{abstract}


sa Wikang Filipino (Commission on the Filipino Language). He serves as Associate Editor for Suvannabhumi, an international multidisciplinary journal of Southeast Asian Studies based in Busan University of Foreign Studies, South Korea. In 2014, he opened a benchmarking undergraduate elective on the "Teleserye," the first to solely study Philippine TV soap opera. 


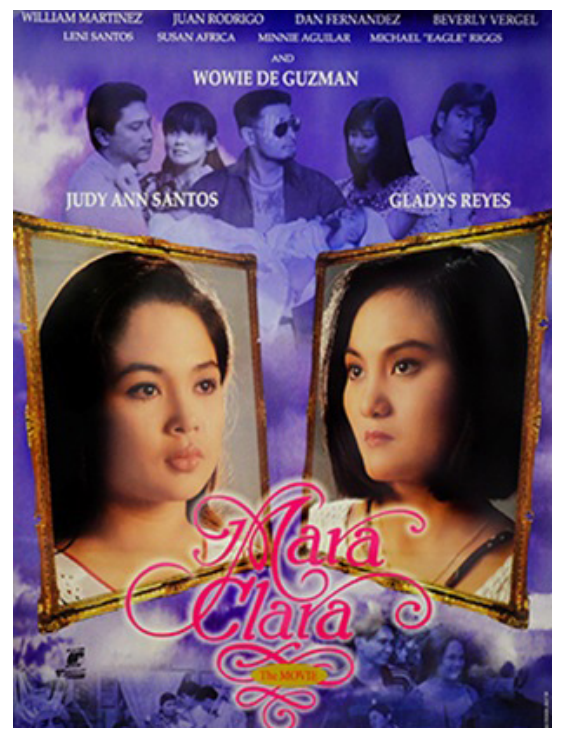

Larawan 1. Si Judy Ann Santos sa pagsasapelikula ng kaniyang soap opera na Mara Clara (dir. Emil Cruz, Jr. at Jerry Lopez Sineneng, Star Cinema Productions, 1996).

Hindi na ipagtatanong pa ang lugar ni Judy Ann Lumagui Santos sa daigdig ng showbiz sa Filipinas (Larawan 1). Sa kasalukuyan, palagiang matatagpuan ang kaniyang ngalan sa talâan ng mga natatanging Filipinong aktres batay sa mga napanagumpayan, sa dami ng mga naipagkakatiwala at ineendorsong produkto, o sa simpleng pagiging "ikoniko"; bagay na hindi agad nahinagap ni Rolando B. Tolentino sa kaniyang sanaysay hinggil sa aktres noong 2000 (103-110), ngunit talaga ngang ang hinaharap lámang ang nakapagsabi. Makahulugan ang dalumat ng $i k o n$ sa pagkakataong ito, lalo kung iuugnay sa debosyon ng mga tagahanga ng aktres na magpahanggang ngayon ay palagiang sinusundan si Santos sa kaniyang mga palabas sa telebisyon, at nakatunghay pa rin sa kaniyang búhay kahit pa higit niyang inuuna kaysa karera ang búhay-pamilya; at maging sa pagturing sa kaniya ng maraming kritiko at mamamahayag ngayon bílang isang aktres na nakapagpanatili ng sariling kasikatan at halaga sa mapanghamon at pabago-bagong takbo ng panahon. Sa pagbaling sa etimolohiya ng salitang ikon, na nagdadala sa atin sa mga pakahulugang "imahen," "pigura," at "representasyon," maaari na nga sigurong ipangatwiran na kinakatawan na rin ni Santos ang minsang paglalarawan ng Manila Times noong Hunyo 23, 2014 kay Nora Aunor at sa kaniyang tagumpay bilang nakapag-iwan ng "a deep imprint on Philippine cinema, having achieved both critical acclaim and mass popularity" ("The Nora Aunor Affair” n.p.). Waring nagiging propetiko tuloy sa bahaging ito si Tolentino nang sabihin niya sa kaniyang sanaysay na "[ang] legacy naman ni Nora [Aunor kay Judy Ann ay]...kung paano ang ordinaryo ay kinakasangkapan para bumenta, kung ano ang idinadagdag na bentahe 
para ito ay tangkilikin ng nakararami" (Tolentino 10). Bukod pa ito sa pagganap na tinutupad ng aktres sa bawat pag-arte, na kaugnay ng gawain ng "representasyon" at wika nga ni Julie d'Acci ay siyang ubod ng telebisyon: 'Representation' is what television is all about, denoting, as the term does, signs, symbols, images, portrayals, depictions, likenesses and substitions" (sa d'Acci 91). Para sa talakay na ito, ang ikonolohiyang tinutupad, ang pag-aaral sa pagiging ikon ni Santos, ay bumabaling sa masalimuot na tagpuan ng mga pakahulugan sa representasyong kinakatawan ng aktres bílang isang texto. Naniniwala akong sa pamamagitan ng pagkakaroon ng ganitong balangkas, higit na mapahahalagahan ang pagka-di mawari [ambivalence] ng representasyon at ng potensiyal nitong makapagsulong at makapagtatag pa ng diskursong makahulugan naman talaga para sa marami, sabihin mang bahagi ito ng pang-araw-araw gaya ng mga teleserye na magpahanggang ngayon ay pinagtataasan pa rin ng kilay ng akademya marahil dahil hindi pa rin matanggap ang balangkas ng Araling Pangkultura na nagsasabing "[the] culture of everyday life works only to the extent that it is imbricated into its immediate historical and social setting" (Fiske 154). Ayon kay John Fiske na siyang sumulat ng sinipi, "[under] these conditions, social experience and, therefore, culture is inescapable material: distantiation is an unattainable luxury" (155). Pilit mang "layuan"—di tulad ng paglayô na iginagawad sa "matataas na uri" ng sining na humihinging tunghan nang may estetikong (at dahil nga roon ay maituturing na "edukadong") kalayuan-hindi na matatakasan ang pagkamakahulugan ni Santos at ng kaniyang obrang teleserye.

Kapwa mga "reyna" ng kani-kanilang panahon sina Aunor at Santos. Marami talaga silang mga pagkakatulad lalo kung susumahin ang kanilang pag-unlad bilang mga pangunahing aktres. Supling ng sistemang studio si Aunor matapos ng ilang panahong pagsali-sali lámang sa mga pakontes sa awitan at pagsubok na magkaroon ng karera sa pag-awit. Sumikat si Aunor bílang isang dalagitang aktres noong Dekada 6o kung kailan malaganap na ang pelikulang tubog sa pamantayang Hollywood at mestisahing artista na nagtakda sa malaong panahon ng estetika ng kulturang popular. Kinakatawan niya ang ideyal ng kayumangging kaligatan na kontrapunto ng lahat ng kolonyal na hulmahan ng kagandahan, isang kagandahang ordinaryo kung baga, isang bagong imahen na kaiba sa lahat ng naitatag na. Papausbong din noong mga panahong iyon ang telebisyon na unti-unting kumakalap ng tangkilik at tumulong din sa pagpapalaganap ng kasikatan ni Aunor, na noong mga panahong iyon ay may hukbo na ng mga tagasunod. Nasaksihan ko mismo ang matinding debosyon ng mga tinaguriang "Noranians" may isang taon na ang nakalilipas nang kataka-takang matanggal si Aunor sa talaan ng dapat sana'y gagawaran ng Orden ng Pambansang Alagad ng Sining na ipinasa ng National Commission for Culture and the Arts at Cultural Center of the Philippines sa Tanggapan ng Pangulong Aquino ("Fans, academe launch initiative to declare Nora Aunor 'People's' National Artist" n.p.). Sa forum na aming ipinatawag nina Dr. J. Pilapil Jacobo, Prop. Jose Mari B. Cuartero, at Prop. D.M. Reyes sa Pamantasang Ateneo de Manila, sumugod ang 
kayraming tagasunod mula sa iba't ibang fans club ni Aunor, karamihan sa kanila na matatanda na't halatang noon pa'y humahanga na sa aktres. Marami sa kanila'y masugid talaga at handang magutom maipakita lámang ang pagmamahal sa aktres. Maaari'y ilan sila sa mga Noranians na naging tahasang kalaban ng mga Vilmanians ni Vilma Santos, ngayon at lalo na noon, at may ilan sa kanilang naging bahagi ng maaalamat na "karahasan" sa labanan ng mga tagasunod. Maaaring sila rin yaong patuloy na naghahatid at sumasalubong kay Aunor sa paliparan kung siya ay lumilipad upang mangibang-bansa para tumanggap ng mga pagkilala sa mga film festival, kung saan patuloy na nagniningning ang kaniyang bituin. Sa lumang orden ng sistemang studio na kontrolado noon ng iilang pamilya, tulad ng mga Perez na prodyuser ni Aunor sa Sampaguita Pictures, pinasisikat ang mga artista upang sundan at hangaang mga ispektakulo upang mistulang pakilusin ang madla na panatilihin ang paghanga na may pagsandig sa pananalig sa birtud at kadakilaan ng halos ordinaryong aktres. Ngunit lalagpasan ni Aunor ang kaniyang pagiging pangunahing ispektakulo ng paghanga [bagaman nagmumula sa pookng karaniwan] at tulad ni Santos ay papasukin ang iba pang pamamaraan ng pagtatanghal. Sa telebisyon, naroroong gumawa siya ng mga drama anthology, pati na rin ng mga teleserye. Ngunit ang pinakamahalaga niyang obrang telebiswal ay ang musical variety show, at sinundan siya ng mga tao linggo-linggo sa kaniyang pag-awit sa malaong palabas na Superstar. Sa yugto ng Superstar, talagang "Superstar" na si Aunor, isang malaganap na texto ng kulturang popular na malawak ang tangkilik sa iba't ibang merkado at may hatid na pagtatanghal mulang musika, pelikula, teatro, at telebisyon - isang bagay na sa papel na ito'y makikitang tinupad din ng ating pangunahing texto bilang isa ring ikon. Papaano nga ba gumulang si Santos sa sarili niyang panahon ng pamamayani ng mga TV network at matinding hidwaan ng mga ito upang mapanatili ang kapwa iginigiit na "pangunguna"? Papaano niya ginamit sa kabuuan ng kaniyang karera ang birtud ng pagiging payak na sinasabing "pamana" sa kaniya ni Aunor? Ano ang naidulot ng ganitong birtud sa kaniya, at sa kulturang popular sa pangkabuuan?

\section{ISANG KRITIKA HINGGIL SA AURA NG ORDINARYO}

Sa ngayon, totoo namang napakaraming sukatan ng pagiging ikon, kabílang na ang pagtasa sa mga talâ ng pagkilala at filmography, maging ng nasusukat nang pagkapatok ng mga pinagbibidahang pelikula at palabas sa telebisyon dahil sa ticket sales, advertising support, at ratings. Ngunit talagang napakahirap tudlain, lalo na ang "lalim" ng impresyon na naidudulot ng isang artista sa larang at sa málay ng madla, bagay na masasabing kaugnay ng katangian ng isang ikon bílang imahen na kapag dinadalumat ay nagdudulot ng sari-sari ngunit magkakaugnay na "notions of picturing, imagining, perceiving, likening, and imitating" (Mitchell 1). Kung ang pag-aaral ng mga imahen bílang ikon ay tinatawag na ikonolohiya, 
at ang pagsasalaysay hinggil sa mga ikon ay humahango sa sinasabi ni Mitchell na "rhetoric of images" (ibid.), tiyak na kayraming maitatalâng saysay hinggil sa naging "pagreretorika" ni Santos at ng kaniyang karera sa loob ng halos 30 taon bílang artista sa larang ng kulturang popular. Madalas nang sinasabing ikon siya ng babaeng api bílang aktres sapagkat malaong kumakatawan sa mahihirap at martir, mapa-pelikula man o telebisyon. Hindi naman maitatangging gayon ang kaniyang naging obra, at totoo namang sa mga gayong pagganap siya naitalaga-sang-ayon sa kaniyang "pagkakapakete" bílang aktres o personal na pagpili bílang isang itinatangi't inaalagaang artista. May ganoong kakayahan si Santos sa kasalukuyan, at dahil bahagi siya ng mga "natatangi", maaari niyang diktahan ang materyales ng pagganap, ang panahon ng pagtatrabaho, at ang kikitain matapos. Kamakailan, nakatakda siyang magbalik sa isang teleserye katambal ang aktor na si Richard Yap ngunit bigla niyang inanunsiyo ang muling pagbubuntis. Nagpaalam na siya sa produksiyon ngunit napagpasiyahan ng network sa hulí na hintayin na lámang siyang makabalik sa trabaho matapos manganak ("Why Judy Ann's New Teleserye Was Put on Hold" n.p.). Gayong "kapangyarihan" ang nakamit si Santos matapos ng maraming taon ng pagiging bahagi ng industriya. Ngunit interesanteng balingan sa pagkakataong ito si Santos bílang makapangyarihang tagapagtatag din ng retorika ng kontemporaneong telebisyong Filipino, lalo na ng isang genreng kilala na ng publiko ngayon bílang "teleserye" - ang genreng masasabing may-pihit-pa-wikang pagsakop ng Filipinong kulturang popular sa tunay namang angkat na soap opera, ang malaong kilala nating seryeng pandrama na sinasabing nagsimula sa Filipinas bandang dekada '6o. Noong 2000 ipinakilala ang dalumat ng "teleserye," una bílang bansag sa "engrande" at "malapelikulang" produksiyon ng ABS-CBN, ang Pangako $\mathrm{Sa}$ 'Yo. Simula noon, kagila-gilalas na naging bukambibig at napabantog ang salita sa maraming diskurso sa midya bílang "imbentong" pangngalan para sa soap opera bagaman magpahanggang ngayon ay hindi pa itinatalâ sa opisyal na mga kronika ng diskurso tulad ng UP Diksiyonaryong Filipino. Hindirin ito nakapasok sa programang Sagisag Kultura ng National Commission for Culture and the Arts, ngunit naitalâ sa artsibo ng mga nasabing natatanging pangkulturang paksain ang "telenovela" na sa ganang akin ay higit na tumutukoy sa mga seryeng mulang Amerika Latina na sumikat kalagitnaan ng dekada '9o. Ngunit isang tanda ng "pagkamalaganap" nito ay ang paggamit na mismo ng mga kalabang TV network para tukuyin ang mga sarili nilang produksiyon ng soap opera. Lumagpas na ito sa hanggahan ng pagiging "Kapamilya." Naging maningning ang bituin ni Santos sa pagbida sa kanonigong soap opera na Mara Clara na mula sa panghapong iskedyul at mahaba-habang pagsasalaysay ay nailipat noong 1997 sa primetime at napilitang magwakas upang tapatan ang sikát na Marimar (sa direksiyon ni Beatrice Sheridan) mulang Mexico, ang telenovela na bumago sa kalakaran ng dramang pantelebisyon sa bansa. Isa pang kanonigong soap opera ang magpapasikat sa kaniya, ang Esperanza, bandang 1999, kung saan niya kakatawaning muli ang aping persona sa karakter ng dalagitang napawalay sa mga kapamilya at naghahanap ng kalinga habang sinisikap balikan 
ang kaniyang nakaraan at hanapin ang mga kapatid at magulang. Si Santos ang naging mukha ng soap opera sa mga panahong nabanggit, sa bungad ng pagsilang ng teleserye. Malaki ang kaniyang naging papel sa "inobasyong" magaganap noon sa soap opera sapagkat siya ang magiging sukatan ng mga sumunod na bituing gaganap sa mga teleserye, kabílang na si Claudine Barretto na sinasabing kaniyang mahigpit na kalaban.

\section{ANG REYNA NG MGA TELESERYE}

Gumulang si Santos sa paggawa ng mga soap opera. Nang magdiwang siya ng ika-27 taon sa larang noong 2013, nagpugay sa kaniya ang ABS-CBN, ang kaniyang network sa matagal na panahon, at binalikan ang lahat ng mga soap opera na kaniyang pinagbidahan sa dokumentaryong "Judy Ann Santos: Her Royal Journey on TV." Sa dokumentaryong ito kinikilala ang kaniyang transpormasyon bílang isang kabataang aktres na naghahanap pa ng kaniyang sulok sa daigdig ng showbiz patungo sa pagiging isang "royalty" na nga at ganap na pagkamit ng titulong “Teleserye Queen" at "Queen of Pinoy Soap Operas" ("Judy Ann Santos' Road to Royalty on Jeepney TV” n.p.), mga epitetong tiyak namang gawad din sa kaniya ng mga "kapamilya" sa kagawaran ng public relations ng kaniyang network. Sa mga press release ng ABS-CBN, halimbawa, sa isang lumabas sa Philippine Star noong Hunyo 13, 2013, pinupuri nang katakot-takot ang aktres sa pagtawag sa gunita ng mga hindi malilimutang pagganap: "Over the years, Judy Ann has endeared herself to millions of $\mathrm{TV}$ viewers in a wide range of different characters such as Esperanza, Krystala, Ysabella, and many more. Her different roles in these favorite television shows eventually earned her the undisputed title of 'Teleserye Queen"' ("Judy Ann Santos' Road to Royalty" n.p.). Sa press release ding ito pinapurihan ng mga dáting kapareha si Santos. Halimbawa, para sa matinee idol na si Piolo Pascual, "I wouldn't be where I am if not for Juday...If not for her, my showbiz career wouldn't be what it is. She is the real soap opera queen" ("Judy Ann Santos' Road to Royalty" n.p.). Para naman kay Wowie de Guzman na malaon niyang nakapareha't singkaraniwan kayâ sila magkabagay: "People can quickly relate to her. Her dedication and love for what she does is incomparable" ("Judy Ann Santos' Road to Royalty" n.p.). Nakatulong din marahil ang maganda niyang imahen upang manatiling kapanipaniwala ang mga papuring ito. Sa sarili kong paliwanag sa isang artikulong may maikling bersiyong nalathala sa magasin na Rogue — sa isa nitong natatanging bílang hinggil sa telebisyong Filipino noong Disyembre 2014-ganito ang aking tinuran hinggil sa kaniyang "pagrereyna": "Judy Ann Santos, is for me, the quintessential teleserye superstar for two things: firstly, she practically grew up in soap operas, and harnessed her talent by growing into various roles that compelled her to fully articulate the Filipino female archetypes; and secondly, she has fully utilized her being seasoned by the soap opera industry to explore the other possibilities of 
her talents" (Sanchez 117). Dagdag ko pa, sa paggulang sa pag-arte sa mga soap opera, naging katangi-tangi si Santos sapagkat mahusay niyang napagsumikapang lagpasan ang madalas na paghahanggahan ng isang genreng telebiswal, ang soap opera, na madalas namang may tiyak na tabas ng mga pagganap at direksiyon ng naratibo (Sanchez 117). Naging lungsaran ito halimbawa ng pagtuklas niya sa posibilidad ng pagiging TV host, recording artist, at prodyuser ng pelikula. Hindi siya naipiit sa malaong paglulugar sa kaniya bílang isang marhinal at kaawa-awang babae, isang bagay na unang napansin at tinukoy na "ordinaryo" ni Tolentino, sampu ng kaniyang iba pang talento bílang artista. Wika pa niya, "[ordinaryo] ang features ni Judy Ann Santos, maging ang kanyang talent ngayon. Hindi pa lubos ang pag-arte, hindi rin lubos na marunong sumayaw at kumanta" (Tolentino 103). Kung susuriin ngayon, may kapangyarihan pala ang gayong pagka-ordinaryong namalas ni Tolentino sa panahon ng pagsikat ni Santos, isang panahon ng edukasyon sa genre ng soap opera na noong mga panahong iyon ay dumaraan sa yugto ng pagbabago. Isa itong kapangyarihang umaakit sa manonood at tumatanggap ng pagkilala, habang naghahawan ng daan patungo sa mga matutuklasan pa habang gumagawa ng mga soap opera. Isang genre na kilala sa katangian ng seryalidad ng salaysay ang soap opera na naglalaman ng "some form of interruption in the flow of the story" ayon pa kay Anna McCarthy (sa Creeber 6o), bagaman sumusunod sa tiyakang pormulasyong tinatangkilik ng manonood. Paulit-ulit mang nakikita si Santos sa gayong hulmahan ng seryalidad, na iniisip kong isa talagang aspekto ng kaniyang pagiging "ordinaryo" sa isang banda, ang sunurang pagsasalaysay-ang paulit-ulit na pagpukaw sa kasabikan ng manonood, ang pagpapanatili ng interesay paggigiit din ng kakayahan at bisa ng kaniyang ikon na lumikha ng kalabisan ng kahulugan.

Ito ring kapayakang unang napansin sa kaniya ang mismong kinasangkapan ni Santos upang maisalaysay_mula sa Kaming mga Ulila (1986) hanggang sa pinakahuling serye na Huwag Ka Lang Mawawala (2013) - ang mga pagpupunyagi ng kababaihang nahaharap sa mga tunggaliang dulot ng mga mapaniil na estrukturang panlipunan. Marami sa kaniyang mga karakter ang nagpamalas ng kakayahang titigan ang paniniil sa babae nang mata sa mata. Sa malaganap na tradisyon ng realismo sa telebisyon, hindi maikakailang ang kakayahan at pasyang gamitin ang birtud na ito sa harap ng mga pagsubok ang naging dahilan upang patuloy na tangkilikin ng madla ang imahen, at maaari, maging ang persona ni Santos na kumakatawan sa lahat ng pagpapahalaga't kahulugang naipaloob dito ng kaniyang karera. Ito rin sa aking palagay ang kaibhan niya sa maraming aktres sa telebisyon, maging sa pelikula, na tulad niya ay tagapaglahad ng mga kasaysayan ng kababaihang Filipino. Mayroon siyang "vengeful power," ani Nestor U. Torre sa isang pagsusuri ng Huwag Ka Lang Mawawala (sa direksiyon ni Malu Sevilla, Jerry Lopez Sineneng, at Claudio Sanchez Mariscal IV) sa Philippine Daily Inquirer noong Setyembre 20, 2013 ("Instructive Lessons from Judy Ann's Drama Series" n.p.), at kahit pa nga "too 
melodramatically achieved" ang naging pagganap ni Santos sa kaniyang teleserye na lantarang nagtaguyod ng "female empowerment" ay nagkaroon ito ng "strong impact in its top female protagonist's story of vengeance and retribution, against all odds" ("Instructive Lessons" n.p.). Ang gayong "vengeful power" ay masasabing produkto ng matagal niyang edukasyon sa pagganap, isang birtud na magtatakda sa kaniya bílang pangunahing bida at bituin ng showbiz sa Filipinas, bílang reyna ng mga teleserye. Ang kapangyarihang ito ay nahango niya sa pagdanas sa laksang kababaihan na kinatawan ng kababaihang Filipino, sa iba't ibang ngalan at katauhan, pagsubok at pagtatagumpay, tagpuan at panahon-Ula, Mara, Esperanza, Diane, Patricia, Princess, Krystala, Jennifer, Ysabella, Jane. Sa teleseryeng pinaksa ni Torre, ginampanan ni Santos ang papel na Anessa, isang babaeng punô ng pangarap at nangangalaga sa tanging yaman ng kaniyang pamilyang maykaya sa isang lunang rural-ang asinan. Nakilala niya ang karakter ng kaparehang si Sam Milby na si Eros, na makakaugnayan niya dahil tatangkain ng binata na bilhin sa kaniya ang lupaing kinalulugaran ng asinan. Mabubuntis siya ng mapang-akin na si Eros, na sa kaniya'y magiging isang marahas at nananakit na asawa. Magiging punò't dulo ng tunggalian ang paglalayô ni Eros sa kanilang anak na lalakíng hindi nakikilala si Anessa. Itong ubod ng tunggalian ang paghuhugutan ni Santos ng pathos ng tauhan, na pupurihin ni Torre sa siniping rebista: "Judy Ann had greater success in vivifying her character's love for her young son, who was forcibly taken from her by her decidedly bipolar husband, played by Sam Milby" ("Instructive Lessons" n.p.). Ang matapang na pakikipaglaban para makapiling ang anak ay ipakikita ng teleserye sa matinding paghahanda ni Anessa: mag-aaral siya ng kickboxing, matututong humawak ng baril, at magiging maalam sa kaniyang karapatan gamit ang batas. Maghuhunos ang probinsiyanang mag-aasin upang maging matapang na babaeng susuungin lahat ng panganib at dahas, maipakilala lámang ang sarili sa anak na napawalay. Sa isang eksena, lihim na sasalubungin at makatatagpo ni Anessa ang anak sa paliparan matapos na malingat si Eros at ang kinakasama nitong si Alexis [KC Concepcion]. Isa iyong sandaling tigib ng pangungulila ngunit maraming balak si Anessa upang makuha ang anak. Sa kabilâng banda, malaganap din ang metriko romanseng tradisyon ng mga gusgusing nagiging prinsesa, ng mga prinsesang dumaraan sa pagsubok, ng mga prinsesang ang kaganapan ay nása pagkakatagpo sa magliligtas na prinsipe na pakakasalan sila't sasaluhan sa ligayang walang hanggan. Masdan na lámang ang kaso ng kinikilalang "katunggali" ni Santos sa larang ng soap opera na si Barretto, na dahil sa may imaheng alta de sociedad ay sa tingin ko'y madalas na ibinabagay sa mga de-kahong nakaririwasang papel (may debate rin hinggil sa kaniyang "pagrereyna" sapagkat tulad ng sa tagisang Aunor at V. Santos, may mga masugid na "tagahanga" rin si Baretto). Magandang kontrapunto ni Santos si Barretto sa paglalatag ng pagpapaliwanag, hindi lámang hinggil sa tradisyon ng pagganap sa soap opera at teleserye-na sa pagkakataong ito'y nagsasanga sa realistiko at romantiko-kundi pati na rin sa mga pananaw hinggil sa pagkatawan ng mga aktres na ito sa mga diskurso ng genre, kabílang 
na ang usapin ng tunggalian ng uri na karaniwang nadadawit sa mga talakayan ng Araling Pangkultura.

Ngunit para sa akin, higit na monumento si Santos ng tunggalian, ng diyalektika, at hindi lámang ng mga isteryotipo't kaasahang lalaging makikita sa soap opera. Mistulang may kabatiran si Santos na ang soap opera, bílang genreng kaniyang kinamulatan, ay tigib ng mga "eksenang nagsisigawan...eksenang nagsasampalan, confrontation," wika nga niya sa isang panayam sa kaniya ni Rommel Gonzales ng Philippine Entertainment Portal ("Judy Ann Santos Says She Is Like Ploning in So Many Ways" n.p.). Subalit ang mga sigawan, sampalan, at kumprontasyong nabanggit ay pahiwatig ng pagbalikwas matapos ng malaong pagtitimpi at pagbatá sa hirap sa bawat pagganap. Nangunguna si Santos sa larang na ito sapagkat tapat ang kaniyang karakterisasyon sa diwa ng tunggaliang kinakabaka ng babae sa lipunang Filipino. Nananatiling paragonal si Santos sa larang sapagkat nagtatag siya ng retorika ng pagganap na palagiang nagsusumikap humigit sa kaapihang siyang lunan ng kababaihan sa estruktura, isang patunay na talagang probisyonal at naging linyado ang unang pagtasa sa kaniya ni Tolentino, nang sabihin ng kritiko na "[lapat] ang pagiging babae ni Judy Ann sa liminal na espasyong inilalaan ng historical na okasyon para maging representasyon nito" (Tolentino 108). May tungkuling lumagpas sa mga pagtataya ng tunggalian ang kababaihan ni Santos, isang hukbo ng kapangyarihan, higit sa kabutihan (sapagkat ang halagahan ay nanatili pa rin sa pagitan ng mabuti at masama, kung susuriin ang namamayaning kaisipang binaryo at patriyarkal). Papaanong liminal lámang ang mga ito? Ang mga kababaihang ginampanan ni Santos ay may isip at lakas na takdaan ang kaapihan. Tumutulo ang luha niya bílang sila ay nagpapamalas pa rin ng katatagan. Mulang pagiging gusgusin at marhinal sa sukal hanggang pagiging edukadong punô ng pangarap, ginahasa, at inagawan ng anak, ang wika ng pagganap ni Santos ay paglaban, paghagilap sa sarili, at pagtamasa sa ganap na ligayang palagiang mailap kaya't nararapat ipaglaban. Makikita ito sa pagtugaygay sa mga pilîng soap operang kaniyang pinagbidahan na tititigan para sa pakana ng papel na ito. Isa pa, kinatawan si Santos ng transisyon ng lumang panahon ng telebisyong Filipino patungo sa "demokratisado" nitong anyo at katayuan matapos ng Rebolusyon sa EDSA noong 1986, isang mahalagang yugto ng kasaysayan ng brodkasting sa bansa sapagkat bílang pagpapatotoo sa mga pakahulugan ng salitang "rebolusyon," nagkaroon nga ng malawakang pagbabago sa industriya na noong panahon ng rehimeng Marcos ay bantay-sarado, hawak ng malalapit na kaibigan o crony, at nagagamit lámang bílang daluyan ng propaganda ng diktaduryang konyugal. Ang yugtong sumunod ay masasabi ring panahon ng higit na "paglaya" ng brodkasting (at dahil nga rito ay lalong pag-unlad dahil sa kabaguhang sinagap nito habang sumasabay sa panahon ng globalisasyon) at ng malawakang Filipinisasyon ng malaganap na diskurso (ang naunang panahon ay mapapansing higit na makiling sa Ingles, lalo sa larang ng pamamahayag at balitaan, maging sa malawak na pagpapalabas ng mga 
Amerikanong drama). Sa pagsusuring unang tinupad ni Benilda S. Santos (sa Reyes 221-36) hinggil sa imahen ng kababaihan sa mga pelikulang lumabas sa pagitan ng mga taóng 1976 at 1986 - na aking inaangkop din sa telebisyon, sapagkat totoo namang magkaugnay ang dalawa sa konteksto ng kulturang biswal sa Filipinasmasasabing napapailalim ang karamihan sa mga papel ni Santos sa kategoryang "image of the Filipina as Idol in the Role of the Suffering Virgin/Wife/Mother" na may balangkas na nagdiriin sa "validity of the role of the Filipina as a long-suffering victim of vicissitudes of life" (ibid. 224). Kasiya-siyang binabanggit din ni Santos sa sanaysay ang dalumat ng ikon bílang pagtukoy sa katauhan ng babaeng "idolo," hinahangaan sa kaniyang pang-araw-araw na pagbatá sa kahirapan, isang "babaeng martir" (ibid. 225) pa nga na tinatanggap ang lahat ng sákit kahit ilohiko na ang pagiging "walang reklamo" (ibid. 228). Pangunahing halimbawa rito ni B. S. Santos ang karakter ni Aunor sa pelikulang Atsay (1978) kung saan "(t)he filmic content goes right down to the everyday, the ordinary, the living rooms of all households, to the world of the lowly atsay" (ibid. 227).

\section{SI SANTOS AT ANG KANIYANG PANAHON SA SOAP OPERA}

Ang pagdawit ni B. S. Santos sa salitang "ordinary" ay agad na pumukaw sa akin sa paggunita ng sinasabi ni Tolentino hinggil sa "aura ng ordinaryo" ng ating paksang aktres batay sa dalumat na hiniram kay Walter Benjamin: "Si Judy Ann ay figurang kumakatawan para sa tradisyonal at ordinaryong gawi ng búhay" (Tolentino 106). Ngunit ang kapayakang ito'y dapat básahin ngayon bílang subersibo kahit pa sa simula ay kumatawan lamáng sa imahen ng kababaihang api na kilalá at tinatangkilik ng masa. Sabihin mang tiyak na may agon na hinarap si Santos sa kaniyang mga hinalilihang (predecessors) sina Janice de Belen at Julie Vega, kapwa mga "prinsesa ng soap opera" ng kanilang panahon, at tinularan niya marahil sa sinubaybayang dramahan at pagdurusa (kahit hanggang libingan, sa kaso ni Vega, na hindi nagawang tapusin ang kaniyang seryeng Ana Liza nang biglaang pumanaw noong 1985 dahil sa isang mahiwagang sakít), mga pangunahing sukatán ng pagiging bida sa isang anyo ng soap opera na bahagi ng sumakabilang panahon ng telebisyon. Inigpawan niya, sa ganang akin, ang mapagtakda at mapagpiit na lugar ng pagkakalapat ng mga tauhang kaniyang kinatawan, pati na rin ng genre na kaniyang malaong kinasangkutan bukod sa pelikula. Bílang bida na "isang kultural na texto, may kaakibat na paghubog sa popular na kamalayan, na may sinisiwalat na mga ideya ukol sa mga tunggaliang panlipunan, pangkasaysayan at modernidad" (Tolentino 3), kinatawan din ni Santos, sa kabuuan ng kaniyang karera, ang makahulugang paghubog sa "teleserye," na tulad niya bílang artista ay itinuring na ordinaryo, marahil sapagkat malaganap, de-kahon, at hindi lumalayo sa kinahiratian at tinangkilik. Ngayon makikita ang mabalintunang ugnayan ni Santos sa mismong genre na kaniyang "binuo" matapos ng panahon ng kaniyang 
paglagi sa pag-arte rito. Sa aking palagay, maituturing na "pundadora" si Santos ng teleserye, bílang pangunahing kinatawan ng lumang rehimen ng brodkasting na nagtatanghal sa naunang anyo ng soap opera, at bílang tagapaghawan at siya na ngang "reyna" ng naging "teleserye" pagtungtong nito sa panahon ng bagong milenyo. Ang kaniyang katauhan, persona, at obra ay tagpuan ng dalawang yugto ng kasaysayang ito, nagsasalungatan ngunit nagsasanib, at patuloy na inaanyuan ang kulturang telebiswal, habang wika nga ni Tolentino ay binibigyan ng "elaborasyon" ng mga pagganap niya ang "panahon ng modernong pagbabago" (ibid. 108). Sa isang matalik na pagbása, mahihiwatigang may tatlong sapin ang bisa ng pagiging ikoniko ni Santos na sa kasalukuyang pagtataya ng papel na ito ay sumasapit na nga sa pagkatha ng telebiswal na genre. Sa unang sapin, makikita ang napansin ni Tolentino sa "hatak" ng persona ni Santos na nagdadala ng pagtangkilik mula sa publiko, at sa panahon ng pagkakasulat ng kaniyang sanaysay, nakapagdadala rin ng muling pagkabúhay sa naluluoy nang industriya ng pelikulang Filipino. Sa sapin ding ito matatagpuan ang nasabi nang kapayakan, ang "aura ng ordinaryo" na may hatak sa mga "kabataang kababaihang may identipikasyon sa ordinaryong kalidad ng bida" (ibid. 103). Ang pagbásang ginawa ni Tolentino rito ay nakabatay sa kritika ng kapital at konsumerismo na nakapagdudulot sa ordinaryo ng "posibilidad ng auratiko" mula pa rin sa pagpapalagay ni Benjamin hinggil sa sining sa yugto ng reproduksiyong mekanikal, at nagdudulot ng katangian sa isang textong pangkultura na maging natatangi kahit ordinaryo sa pamamagitan ng diseminasyon (ibid. 105). Sa sapin ding ito napahalagahan ni Tolentino ang kapayakan ni Santos sa kabila ng "mukhang mamon" niyang katangian noong papasikat ang aktres. Interesanteng masdan ang paglalarawan ng kritiko sa kaniya gamit ang "hulmahan ng mga naging batang artista" (ibid. 106). Wika pa niya: "Hindi mestisahin, hindi matangkad, hindi kanluranin ang features at pangangatawan. Hindi rin naman Filipina beauty - kayumangging-kaligatan, mapungay ang mga mata, oval face, at iba pa. Ang pisikalidad at physiognomy ni Judy Ann ay ordinaryo. Parang kahit sino ay maaaring maging Judy Ann, nagkataon nga lámang na si Judy Ann ang naging Judy Ann Santos" (ibid. 106).

Subalit hindi na nagawang sumapit ng diskurso ni Tolentino sa ikalawang sapin bagaman nagawa niya ang paglalarawang sinipi sa naunang talata-na mabuti yatang tawaging "ikonikong panunukat" na tinutupad ng kulturang popular sa bawat artista [hindi nga ba ganito rin ang ginawa, at patuloy na ginagawang panunukat kay Aunor upang igiit ang kaniyang pagiging bukod, natatangi sa lahat?; masdan na lámang ang popular niyang mitolohiya: dáting tindera ng tubig sa tren sa Bikol kaya animo'y Cinderella; maliit at kayumanggi na kontrapunto ng matatangkad at mestisahing padron ng mga bidang babae sa panahon ng malalaking studio; at halos manipis ang pagitan ng tunay-na-búhay at ng mga búhay-na-ginampanan, ayon nga sa minsang pagpapalagay ni Neferti Xina M. Tadiar (227)]. Napansin din ni Tolentino na bílang bida, si Santos ay may "panghatak" na "kasarian at 
sexualidad na may kakayahang magbigay elaborasyon sa panahon ng modernong pagbabago." Sinipi na sa naunang talata ang sa panahon ng modernong pagbabago ngunit muli itong tinititigan ngayon sapagkat makahulugan sa pagpapamulat ng ambag ni Santos hinggil sa mga bagong pagpapahalaga, halimbawa, na ipinakikilala ng mga pagganap ng aktres, lalo sa talakayan hinggil sa usaping pangkababaihan, kahit pa "nostalgia para sa makabagong teknolohiya" ang pang-aapi sa kaniya "sa pamamagitan ng maramihang labadang kailangang linisin" (ibid 107), lalo na sa Mara Clara kung saan siya namasukang katulong sa mansiyon ng sarili niyang mga magulang. Samantalang maaari pa ngang pagtalunan kung totoo ngang matagumpay si Santos sa diskurso ng kaniyang pagganap-maging sa pagganap bílang kasalukuyang babae-sa paglikha ng mga soap opera, at di naglaon, ng mga teleserye, ang totoong pahiwatig ng praseng sa panahon ng modernong pagbabago ay tumutukoy sa matititigang phenomenon sa ikatlong sapin, na nilalagpasan na ang diskurso ng katauhan at persona, na kapwa kumakatawan sa sasisag at dalumat na "Judy Ann Santos." Sa sapíng ito mababása ang sari-saring diskursong nalilikha ni Santos at ng kaniyang karera na masisinop mula sa pagpapalalim ng paghimay sa una at ikalawang sapin. Maihahalintulad ang metodo kong ito sa ipinakilalang "rhetoric of the image" ni Roland Barthes, kung saan sinasabing mayroong denotasyon, ang literal na pakahulugan ng imahen, at konotasyon, na naglalaman naman ng masagisag at kodipikadong pakahulugan ng nasabing imahen, sang-ayon sa sistemang kontekstuwal ng lipunang minulan ng imahen (Image Music Text 3251). Sa ganang akin, hindi sapat ang pagtitig lámang sa pag-uugat at paglago ng imahen—sa kasong ito, ng ikon—bílang sagisag. Ang lunggati ay hindi lámang dapat magtapos sa pagkakatuklas, pagkakalutas sa kislap-diwa ng isang imahen habang tinatanggap ito sa isang lipunan, habang hinaharap bílang isang makahulugang danas, tulad ng sa isang tula, na inilalarawan ng New Critic na si W.K. Wimsatt, Jr. bilang "verbal icon," isang "verbal sign which somehow shares the properties of, or resembles, the objects which it denotes" (x). Ang sagisag na ito ay transdiskursibo, lumilikha ng iba pang diskurso hindi lámang sapagkat, wika nga ni Michel Foucault na nagpauso rito, may kakayahan itong makapagtulak ng iba pang diskurso (sa Rabinow 114), kundi dahil likás din nitong pinaglalabanan ang "pagkakadisiplina" rito ng mga umiiral na pananaw.

Bílang isang ikon ng kaaliwang Filipino sa telebisyon, si Santos, ang kaniyang karera't ouvre sa soap opera lalo na, at ang iba pang umaangat na diskursong dulot ng kaniyang dalumat, ay nagtatatag ng sari-saring wika-at pagsasawika-na maaaring tayaing dala ng kakayahan mismo ni Santos bílang ikon na kamtin ang sinasabi naman ni Barthes sa aklat na Sade Fourier Loyola na pagiging awtor. Ang pagiging awtor na ito ay pakikibahagi sa gawain ng "deduc(tion), combin(ation), arrange(ment), endlessly produc(ing) rules of assemblage" (4). Kung iuugnay sa usapin ng soap opera at teleserye, nagiging isang interesanteng parirala ang rules of assemblage na maaaring maglarawan din sa pagiging batay sa pormula ng genre 
kung saan sumikat at umunlad si Santos. Sa Speaking of Soap Operas, tinalakay ni Robert Allen ang mahabang kasaysayan ng soap opera na sinasabi niyang hubog ng mithiing tunghan ang mga tagapakinig na babae-sa yugtong una itong sumikat sa radyo-at alayan sila ng mga kuwentong salamin ng kanilang domestikong búhay. Sa pagsasabing "[the] soap opera is and always has been a narrative text in service of an economic imperative" (100), binigyang-diin ni Allen ang halaga ng pagsasaalang-alang sa panlasa ng mga tumatangkilik na nagtutulak para sa mga nagpapatakbo ng mga de-seryeng drama na hulihin ang kanilang kiliti-mula noong yugto ng radyo hanggang sa kasalukuyang panahon ng digital television-at sumunod sa mga tanggap na moda upang manatiling kinasasabikan at sinusundan ang kanilang produkto. Ang tagal ni Santos sa genre ng teleserye ay patunay sa kaniyang tagumpay na sumunod sa "imperative" na ito. Ngunit ang pagsunod sa "imperative" na ito ang nagtutulak din sa kaniya bílang ikon na makipaglaro, maging mapaglaro sa píling ng mga batas at pagtataya ng kaniyang genre. Sa isang poskolonyal na kontekstong tulad ng sa atin, isang tanging pagkakataon si Santos ng pagtatanghal ng kakayahan ng lokal na "linlangin" ang banyaga - sa kasong ito, ang soap opera - sa láyong sakupin ito, na yumugto na nga sa ganap na "pagpapangalan" dito bílang teleserye, 15 taon na ang nakararaan. Si Santos ang muog ng sandaling nabanggit, ang paggigiit ng kaakuhang Filipino ng soap opera sa Filipinas, na lohika ng rebolusyon sa telebisyon matapos ang EDSA Revolution. Bílang teleserye, na kasalukuyang resulta ng mga pagkakaanyo rito ng kasaysayan ng telebisyon sa bansa, kinakatawan nito ang kabuuang pananaw-mundo ng mga kontemporaneong tagapagtangkilik, sa gabay (o kontrol) ng negosyong nagtatakda nito, sa ngalan ng pakikibahagi sa mga kairalang nagpapanatili sa kanila sa poder ng kapangyarihan. Kayâ tama rin si Tolentino sa kaniyang tinuran na "ang familyaridad sa ordinaryong karanasan ang siyang nagpapatangkilik sa manonood na sustenahin ang mga pelikula, produkto, at serbisyong ibinebenta ni Judy Ann. Hindi hiwalay ang produksiyong ito sa motibo para kumita at magbigay-aliw dahil dito nalilikha ang aura ng ordinaryo sa figura ni Judy Ann, isang ordinaryong female subject na hinugot sa hanay para itampok bílang extra-ordinaryong nilalang sa showbiz" (109). Ngunit kailangan ngang makita ang bisa ng pagiging ikoniko ni Santos sa pananaw na heneriko, lalo't ang pagkakapangalan sa soap opera bílang teleserye ay isang usapin ng genre, ng tipolohiya, o pag-uuri, o kategorisasyon ng mga programang pantelebisyon, at ng mga panitikan sa pangkabuuan. Si Santos, sa mula't mula, ay minamalas ng papel na ito bílang kalahok sa pagbuo ng teleserye, na isang nakapagsasariling genreng telebiswal na nag-uugat sa una nitong anyo, ang soap opera, at dinatnan ang hiwalayan ng mga siglo na mistulang may pagkasumpong sa isang kaakuhan, isang pambansang kaakuhan. 


\section{ANG OBRA NI SANTOS BÍLANG TEXTO, BÍLANG KASAYSAYAN NG TELESEYE}

Ano-ano nga ba ang mabubulatlat sa mga soap opera at teleserye ni Santos na makapagdudulot sa atin ng higit na pagkaunawa sa pag-unlad ng genre ng teleserye na sumilang sa Filipinas, at "iniluwal" mismo ng aktres sa pamamagitan ng kaniyang dalumat at praktika? Makabubuting masdan muna ang malakihang larawan ng karera ni Santos sa pagganap sa mga ito bílang panimula. Sa hiwa-hiwalay na talâng sinangguni ko mula sa internet [kabilang na ang Wikipedia, sapagkat wala namang opisyal na website si Santos; ganito ang kinakaharap na hámon ng sino mang mag-aaral ng teleserye - may kakulangan talaga sa mapagtitiwalaang data o artsibo ng mga palabas sa telebisyon sa Filipinas, hindi tulad sa pelikula kung saan may mga lawas na ng pagtitipong natupad sa pana-panahon; kaya sinisikap ng artikulong ito na humawan ng landas para sa higit na masinop at metodikong pagtitipon ng impormasyon sa pamamagitan ng salítang pagsusuri ng mga matatagpuang talâ], makikitang gumanap siya sa labinlimang soap opera/teleserye mulang 1986 hanggang 2013: Kaming Mga Ulila (1986), Ula, Ang Batang Gubat (1988), Mara Clara (1992), Gimik (1996), Esperanza (1997), Sa Puso Ko, Iingatan Ka (2001), Basta't Kasama Kita (2003), Krystala (2004) Sa Piling Mo (2006), Ysabella (2007), May Bukas Pa (2009), Habang May Buhay (2010), Gimik 2010: The Reunion (2010), 100 Days to Heaven (2011), at Huwag Ka Lang Mawawala (2013). Sampu rito ay kaniyang pinagbidahan; ibig sabihin, siya ang pinakatampok ang pagganap (Larawan 2). Samantalang tatlo rito ay masasabing cameo lámang o pagganap sa isang kontekstong multikarakter. Ang lahat ng mga ito ay mailalarawang nása anyo ng melodrama, ngunit may ilang inobasyong masasabing hindi realista na inilangkap, gaya ng Krystala na isang fantaserye kung saan gumanap si Santos na isang "katutubong" superhero, at Basta't Kasama Kita na may isahang romansa at kuwentong pulis-imbestigasyon ngunit pinatatakbo ng maliliit na kuwento ng mga kasong kriminal na tulad ng sa mga kilaláng serye sa Amerika. Maaari ring maipailalim sa hindi realistang paglalahad ang Ula dahil malinaw namang tinatawag nito ang gunita ng primitibismo at mga kilaláng kuwento ng paglaki at pagkamalay sa sukal. Halos lahat ng mga seryeng ito'y kinatatampukan ni Santos na may kapareha maliban sa Kaming Mga Ulila, Ula, May Bukas Pa at 100 Days to Heaven kung saan kapwa siya itinampok sa isa o ilang episodyo. Patunay ito sa patuloy na pagsunod ng mga pagganap ni Santos sa molde ng romanse na isang mahalagang sangkap ng isang teleserye, sang-ayon sa pag-uugat nito sa soap opera. At gaya nga ng nabanggit na, ginampanan ni Santos sa mga ito ang papel ng babaeng ngangayunin na nahaharap sa sari-saring pagsubok ngunit itinakda namang mapanagumpayan ang bawat balakid. Wala siyang mga naging period na pagganap. Samantala, sa pagkakatanda ko, tanging ang Ula, Ang Batang Gubat at Mara Clara lámang ang hindi ipinalalabas sa panggabing "primetime"; ang Ula ay sa dapithapon sinusubaybayan samantalang matagal na namayani bílang panghapong drama ang Mara Clara bago ito pinasinsin at inilipat sa gabi. Walang 
ibang talâ na nasangguni hinggil sa Kaming Mga Ulila bukod sa mababása sa ilang sulatin, maging sa Wikipedia, na nagsasabing ginampanan ni Santos dito ang papel ng isang batang palaboy. Ang unang apat na seryeng pandramang kinatampukan ni Santos ay tinatawag pang soap opera - o marahil "telenobela" sa kaso ng Esperanza, na kasabayan ng Mula sa Puso, na matagumpay na naglungsad sa karera ni Barretto, at tinawag sa pagpapakilala rito noong 1997 ng ABS-CBN bílang "telenobela," alinsunod sa malaganap na pagtangkilik ng marami sa "Tagalisado" o dubbed na telenovela. Ang mga sumunod ay binansagan nang "teleserye" sapagkat ipinalabas matapos ang Pangako sa 'Yo at naglalaman pa nga ng iba pang baryasyon ng anyong nabanggit tulad ng fantaserye, pulis-imbestigasyon serye, at nurse/ medical serye sa kaso ng Habang May Buhay. Sa maikling pagtatalâ pa lámang na ito sa "kasaysayan" ng karera ni Santos ay marami na táyong maimumunakala sa anyo ng teleserye sa Filipinas. Una na riyan ang hinggil sa pagiging tubog nito sa kasaysayan ng pagbabago, ng "rebolusyon" ng soap opera patungo sa pagiging teleserye. Ang kabuuang oeuvre o lawas na ito ay tanda hindi lámang ng isang paggulang sa pagganap na ipinaliliwanag ko na nga sa mga naunang seksiyon kundi pati na rin sa mga naging direksiyon ng pag-unlad ng genre na "ipinatupad" kay Santos habang umaarte siya sa mga ito. Masdan na lámang halimbawa ang unang soap opera niya na Ula na nagpakilala sa kaniya bilang artista.

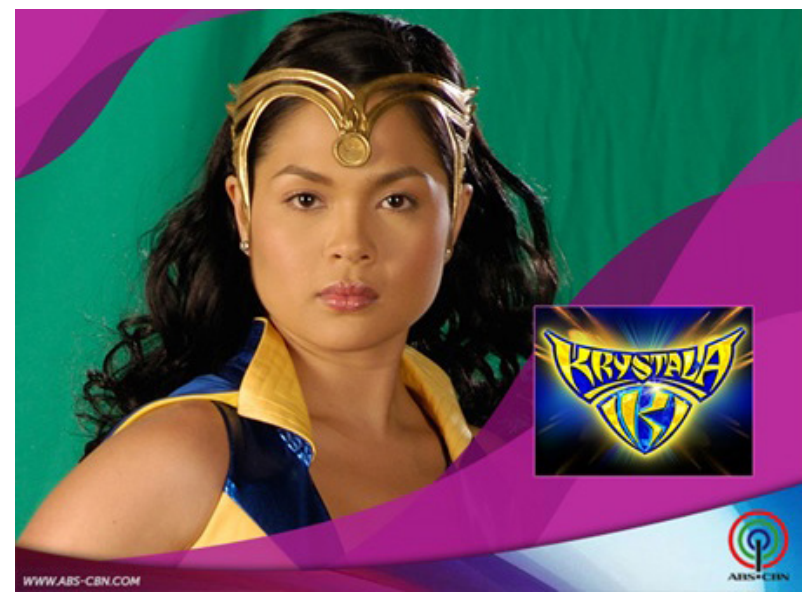

Larawan 2. Si Judy Ann Santos bílang title character ng Krystala (ABS-CBN, 2004).

Ang Ula bílang soap opera ay makikitang sakóp pa ng rehimen ng lumipas na lumang orden ng brodkasting. Direktor ni Santos dito si Argel Joseph, kilala sa maraming produksiyong pantelebisyon at una niyang nakatrabaho sa Kaming mga Ulila. Isang batang ulila rin ang papel ni Santos bílang si Ula na napadpad sa gubat at lumaking kasáma ang isang ermitanyo na nagsisilbing tagapangalaga at bukal ng 
karunungan sa kaniyang pakikipagsapalaran. Magugunita sa pagganap ni Santos sa papel na Ula ang mga naunang pagganap nina De Belen at Vega, na bukambibig ang kasikatan at karibalan sa soap opera at pelikula nang papasikat pa lámang siya. Si De Belen ay si Flordeluna, ang nag-iisang anak ng mga Alicante na nagmimithing panatilihin ang kabuuan ng kaniyang pamilya kahit namatayan ng ina at kailangang pakisamahan ang madrasta; si Vega naman ay si Ana Liza, ang batang kahit dukha at dumaranas ng pang-aabuso ay nananatiling busilak ang puso at mapagmahal sa kapwa. Ang mga pagganap na ito ay pagganap sa isang primal na tauhan, ang pigura ng batang inaagaw ang kawalang-malay ng mga paghihirap at maagang trahedya sa búhay, isang batang dumaraan sa isang proseso ng edukasyon. Sa matagal na panahon, umiral ang soap opera sa Filipinas bílang salaysay ng mga kabataang tulad nina Flor, Ana Liza, at Ula, na dumaraan sa matinding pagsubok at nananatiling nása panig ng kabutihan bumalong man ang luha at mundo ma'y magdilim. Iyon ang kanilang edukasyon. Agad na sasabihing hubog ito ng didaktikong minulan ng mga salaysay na nakatanim sa ideolohiya ng inosenteng pagpapatirapa at kababaang-loob, bagay na madali namang makita sa idealisasyon ng kabataang kahit maharap sa matinding mga pagkawala't pagwawalay ay mananatiling nanalig sa kabutihan ng daigdig at pag-iral ng makatwirang diyos. "Napanood" na natin ang mga ganito sa Sinakulo na hango sa Pasyon, na kuwento ng Kristong minsang nagsabi na ang makapapasok lámang sa kaharian ng diyos ay mga bata. Ngunit ang panahong minumulan ng mga soap opera na ito ay ang magulo at magalaw na panahon matapos ng pagkakapaslang kay Ninoy Aquino na magtatapos nga sa pagdulog ng mga tao sa kalye upang patalsikin ang diktador at kaniyang pamilya. Wari bang bagong Pasyon ang mga kuwento nina Flor at Ana Liza, na nasagap pa ni Ula ang diwa pagdating ng 1986, at ng mga sumunod pang mga soap opera na panonoorin sa bagong-bihis na mga estasyon ng telebisyon. Isang ordinaryong diskurso ang kinasasangkutan ng mga kabataang tampok sa mga soap opera sa yugtong ito ng kasaysayan ngunit isang masagisag ding tanda ng tila ba pag-ahong muli ng brodkasting - at ng genre siyempre - tungo sa higit na sariwang pagbabago. Dapat na ituring ang pagkatawan ni Santos sa Ula na monumento sa dramatikong kamalayan ng lumipas na rehimen, isang gawain ng pagsuso sa tradisyong api man sa simula ay tila ba nakatakdang magtulak ng pagbalikwas (Hindi nga ba kamukha ng paglabas ng mga tao sa libing ni Vega noong 1985 ang libing ni Ninoy, at ang pagkilos ng mga tao sa EDSA?). Kung ang mga kabataang itinampok ng mga nabanggit na soap opera ay yaong mga sinasabing "hindi makabasag-pinggan" (sa kaso ni Ula, wala naman talagang pinggan sa gubat at sa búhay niyang malaTarzan), huhulagpusan ni Santos ang kaniyang pagiging marhinal at walang muwang pagsapit niya sa Mara Clara (sa direksiyon at panulat ni Emil Cruz Jr.) na itinuturing sa mula't mula na naglungsad sa kaniyang karera bílang kaabang-abang sa larang ng soap opera. Sa mga panahong iyon, ang mga serye ay ipinalalabas nang matagalan at tanyag sa mga malalapot na banghay na sadyang nagpapahaba ng istorya. Ang Mara Clara, halimbawa, ay ipinalabas nang humigit-kumulang limang 
taon, at nabago pa nga ang takbo ng istorya matapos mamatay ang kontrabida. Isa itong dramang panghapon, namayagpag sa oras na nabanggit, sa oras kung saan talaga madalas itinatalaga ang mga soap opera matapos ang 1986. Bago na ang pangulo nang mga panahong ipinakilala si Santos at ang kaniyang kontrabidang si Gladys Reyes sa dramang iyon hinggil sa dalawang batang nagkapalitan, sadyang ibinaligtad ang mga kasalukuyan at tadhana. "Ikaw (ay) ako ngayon, at ako'y ikaw," wika nga ng koro ng theme song na paggigiit sa komplikadong sitwasyon ng dalawa. Lumaking mayaman ang karakter ni Reyes na si Clara sa piling ng mga del Valle, ang mga tunay na magulang ni Mara, na ginampanan naman ni Santos. Si Mara naman ay lumaki sa isang kahig, isang tukang búhay ng mga Davis, ang mga magulang ni Clara. Magtatagpo ang mga dalagita at magsisimula sa gayong tunggalian ang pagkakatuklas nila sa lihim na itinalâ pala ng gumawa ng pagpapalit sa isang diary, na kapagdaka'y magiging paksa ng ilang linggo ring pagtatanong at paghahagilap ng mga karakter. Isang kuwento ng gantihan ang Mara Clara, puspos ng karahasan, lalo sa mga kababaihang sangkot sa kuwento.

Mistulangwalang balak magtapos ang Mara Clara-halos epikal nanga salubhang kahabaan tulad ng mga naunang Flordeluna at Ana Liza - hanggang sa yanigin ang buong bayan ng pagsikat ng telenovelang pinagbibidahan ng Mexicanang mangaawit na gumigiling sa tabing-dagat at bibighani sa isang matipunong asendero na sakay ng kabayo. Malakas sa panghapong programa ng ABS-CBN ang Mara Clara at ito ang naipantapat sa noo'y nagsisimulang phenomenon ng mga telenovelang angkat at sumasailalim sa Tagalisasyon. Samantalang ipinagpatuloy ni Santos ang kaniyang pagganap sa pinaigting na't pinabilis na takbo ng istorya (nilangkapan pa ito ng isang bersiyong pampelikula pagkatapos), unti-unting nagbago ang kalakaran ng mga soap sa telebisyon sapagkat nakatikim ang mga tao ng kakaibang putahe, wika nga. Hindi na rin dapat ipagtaka sapagkat hindi naman nalalayô ang kuwento ng mga ito sa ating konteksto. Bukod sa mga nagpupunyaging babaeng dumaraan sa matitinding pagsubok (o mga batang babae na napawalay sa magulang dahil sa biro ng tadhana), buháy sa mga telenovelang angkat ang ilang tandang totoo rin sa konteksto natin bílang bansang dáting sakóp ng Espanya, at pinamamayanihan ng mga estruktura ng kaapihan: ang pamanang asyendang may empleyong mga tagapaglingkod sa rural na puwang; ang presensiya (o ispektro) ng mga tanda ng Kristiyanismo tulad ng imahen ng Mahal na Birhen, pag-aantanda sa mga sandali ng pagkagitla o pagpapatuloy sa isang gawain, ng pigura ng pari, ng espasyo ng simbahang Katolika; at ng pamilyar na ugnayan ng mga uri sa tagpuang urban. Wala mang karaniwang imahen ng mga barung-barong dito (na pamana ng "tradisyon" ng poverty pornography at pananaw na Lino Brocka mulang 1980) na agad-agad maihahambing sa magagarang mansiyon tulad ng sa Mara Clara. Ang diwa ng salaysay ng mga telenovela ay agad na pumukaw dahil sa pamilyaridad ng mga tao sa sistema ng mga tandang namamalas. Ngunit ang totoo talagang pumukaw sa mga tao sa mga telenovelang tulad ng Marimar ay ang bilis ng pagkakalahad 
ng mga ito, tiyak ang hanggahan at bago sa karansang Filipino kung soap opera ang pag-uusapan. Ang mga naunang Flordeluna (1978 hanggang 1986) at Ana Liza (1980 hanggang 1986) ay tumakbo nang matagal. Ang Mara Clara ay tumatakbo na nang halos anim na taon, mula 1992, noong pukawin ang madla ng mga telenovela. Binagong ganap ng mga telenovela ang pagkamálay ng manonood sa temporalidad, na maaaring masabing hubog pa rin ng matagalan at walang-pagmamadaling pagtatanghal ng mga komedya, na ayon pa nga kay Doreen G. Fernandez ay kaibang-kaiba ang "sense of time" sapagkat ang "drama" sa katutubong konteksto ay "definitely non-Western, their pace leisurely, their enjoyment unhurried" (8). Dumaan sa negosasyon ang soap opera, sa pamamagitan ni Santos at ng Mara Clara, upang harapin ang kabaguhang hinihingi ng nagbagong kagawian ng manonood. Masasabi kung gayon na ang Mara Clara ay isang panulukang bato ng mga pagbabagong yayakapin ng soap opera sa Filipinas sapagkat ang pagkakalipat dito mulang hapon patungong gabi ay patunay sa patuloy na pagigiit ng Filipinong soap opera sa kakayahang tumugon sa "banta" ng mga angkat, bagay na nakapaloob sa iniulat na pagtugon din ng ABS-CBN sa lubhang mga pagkalugi sa programming nang "bagyuhin" ng telenovela (Rimban, 44-53). Naging mukha si Santos ng pagsusumikap ng soap opera sa bansa na makasabay sa higit na kawili-wiling mga telenovela na unti-unting dumami matapos ang Marimar. Matapos ng pagtanggap ng Mara Clara at pati na rin ni Santos sa hámon ng higit na mas mabilis na paglalahad, maigting na pagsasalaysay, at tiyakang pagwawakas, sasailalim pa sa mas maraming pagbabago ang soap opera sa Filipinas. Kakailanganin ng soap opera ang ganitong paghahanda sa yanig ng globalisasyon (na malaon na rin namang nangyayari sa patuloy na pag-angkat ng mga serye at dramang Amerikano) sapagkat ilang taon pa ang lilipas ay magkakaroon naman ng pagkawili ang mga Filipino sa mga tatawaging "Asianovela" o mga seryeng angkat mulang Tsina, South Korea, at Japan. At magiging bahagi pa rin si Santos ng mga reimbensiyong kakaharapin ng soap opera sa mga pagsusumikap niyang itindig ang sarili sa gitna ng daluyong ng globalisadong kabaguhan.

Sa isang lumitaw na teksbuk para sa Humanidades noong 20oo, isang aklat na may pitak sa lokal na sining at akda nina Patrick D. Flores at Cecilia Sta. Maria de la Paz, interesanteng balikan ang naging pagpapaliwanag hinggil sa anyo ng soap opera noong mga panahong iyon. Tinawag nilang "format" ang mga sumusunod na anyo ng soap opera: [1] "ang serial na araw-araw lumalabas at pinapatakaw ang mga manonood sa kabanatang aabangan; katulad ng dula sa radyo at nobela sa komiks, ang pagsubaybay sa serial ay nagiging kaugalian na, tradisyon sa pang-araw-araw na kultura"; [2] "ang telenovela na nagwawakas sa loob ng takdang panahon"; at [3] "ang drama anthology na lingguhang presentasyon ng mga madudulang sitwasyon na kung hindi orihinal na katha ay nakabatay sa sulat o kaso sa korte" (78-79). Anila, sa [1] napapailalim ang mga tulad ng Mara Clara, Flordeluna, at Ana Lisa, samantalang sa [2] naman napapailalim ang Marimar. Sa ikatlo naman inihanay 
ang tulad ng matagal sinubaybayang Lovingly Yours, Helen at Ipaglaban Mo, na kamakailan ay nagbalik sa eyre. Kung susuriin ang mga "format" na ito, makikitang may itinataguyod nang anyo ang soap opera noong mga panahong iyon. Kahawig man ng kaurian ng mga soap opera at drama series ng madalas na "ginagaya" na mga modelong Amerikano, nais kong isipin na may mga litaw na kaibhan ang soap opera sa Filipinas. Sa Estados Unidos, may dalawang pangunahing oras ng palabas na maaaring ituring na pangunahing paraan sa pag-uuri ng soap operaang daytime at primetime. Ang mga palabas sa daytime ay umeeyre sa pagitan ng 2 n.u. hanggang 6 n.g. (412st Daytime Entertainment 2013-2014. Emmy Awards General Rules and Procedures), samantalang ang sa primetime naman ay sa pagitan ng 6 n.g. hanggang 2 n.u. (67th Primetime Emmy Awards 2014-2015 Rules and Procedures). Bagaman ginagamit din ang ganitong pag-uuri sa Star Awards ng Philippine Movie Press Club na mayroong mga kategoryang "Best Primetime TV Series" at "Best Daytime Drama Series," ang mga soap opera, kung babalingan natin ang paliwanag nina Flores at de la Paz ay hindi talagang nagbabatay sa oras ng pagpapalabas, at dahil nga ganoon ay may sarili nitong pag-aanyo at pag-uuri sa sarili. Lahat ay pawang materyales ng soap opera, may pinagmumulang tabas na marahil hubog din ng kagawian ng panonood, mga pagkukunan ng network, at malawakang takbo ng brodkasting. Sa ngayon, mapapansing nakakalat ang mga teleserye sa lahat ng oras ng pagpapalabas - may mga teleserye sa umaga hanggang magtanghalian, mga teleserye matapos ng mga noontime show, at mga teleserye sa gabi matapos ng balitaan. Halos sakupin na ng teleserye ang programa ng mga network ngayon. Madaling sabihin na kahit ganito, ang mga palabas na drama ay nakasalig lámang pala sa Amerikanong hulmahang nakatuon sa mga soap opera ng daytime na ipinalalabas lámang nang "five-day installments" o tinatayang "flexible and adaptable narrative form, capable of many kinds of variation across temporal and national contexts" (Creeber 61). Madali ring punahin ito, gaya ng ginagawa ng ilan sa social media, kung ang batayan lámang ng mga "nararapat tangkilikin" na drama ay yaong batay sa mga drama mulang Amerika na may iba-ibang "set of serial conventions" tulad ng "episodic forms of narrative" at "other forms of primetime drama" gaya ng mga sumikat na seryeng medikal, batas, at imbestigasyon (ibid.). Ngunit ang mga soap opera sa Filipinas - ang mga teleserye natin-ay hindi ganito. Mga katangiang panlabas ang mga ito na madaling punahin at ikompara sa mga batayang banyaga, ngunit hindi sapat ang manatili sa totoo namang paimbabaw na pagbása, pagtaya sa soap opera bílang teleserye. Isang magandang kaso ng galíng at sariling bait ng soap opera sa Filipinas ang naging tugon Mara Clara sa harap ng tuwirang "banta" ng banyaga. At higit na makikita ang mga ito sa pagsusuri ng panloob na katangian ng soap operang Filipino na nainternalisa mismo ni Santos sa mga pagganap.

Marahan ang naging pagsunod ng mga soap opera sa pangangailangang pagbabago-nabiglaang tinawagng mga network noon na mga telenobela-matapos 
ng pagbabagong anyo ng primetime sa Filipinas na malaong pinaghaharian ng balitaan, cartoons, o mga angkat na serye mulang Amerika. Ang pagtawag sa mga ito bílang "telenobela" ay tiyakang maimumunakalang pagsunod sa uso, ngunit sa matalik na pagsusuri ay masasabi ring may-pihit-pa-wikang simula ng "pag-aaral" ng anyo ng telenovela, na isang tanda ng paglagpas sa mga narating ng proseso ng pagsasalin na kailangan upang matupad ang dubbing. Sa prosesong ito naisasalin din ang kamalayang pinamumuhatan ng texto, at ang kamalayang ito, tulad ng sa atin, ay kamalayang poskolonyal, nagpapatuloy na iginigiit ang sariling kalinangan kahit pinipi ng wika at kamalayang Espanyol. Ang ganitong "pakikipagtunggali" sa mga puwersang nakapampipipi ay mistulang hinaharap din ng mga pagganap ni Santos sa mga sumunod pa niyang mga drama. Sa ganitong balangkas higit na nagiging matingkad ang kaniyang mga papel, na sinimulan na nating basahin sa mga naunang seksiyon bílang pagpupunyagi ng kontemporaneong babaeng Filipino. Ang ganitong pagkakapagtatanghal (performativity) ng kasarian sa mga papel na yaon ay muling pakikipagtagpo rin sa kasaganahan, kasarian (variousness) ng mga pagpipiping dala ng hirarkiko't bertikal na kamalayang dulot ng pagkakasakop. Sa Esperanza (sa direksiyon nina J. L. Sineneng, Rory Quintos, at Don Cuaresma), kung saan daraan ang karakter ni Santos sa katakut-takot na pang-aapi, kabílang na ang pagdanas sa pandarahas ng mga kontrabidang mayroong tinatawag na "guns, goons, and gold," naipahiwatig ang mistulang pagsuri na mismo sa kalabisan ng masama na halos hindi na kapani-paniwala ang pusok sa pagsupil sa pag-asa ng bida. Sa teleseryeng ito, napanood si Santos na dumaranas ng pisikal at emosyonal na sákit mula sa iba't ibang panig. Paulit-ulit ang mga pagsubok sa búhay ni Esperanza habang hinahanap ang mga kapatid at magulang at sinusubaybayan ang kaniyang bawat pasyon at resurkesiyon. Maaaring makapaghayin ng "gasgas" na tugon hinggil dito, sang-ayon na rin kina Flores at de la Paz: "patuloy na gumugulong ang (ganitong) kapalaran ng soap opera sa Filipinas...dahil manhid at pasibo ang publiko, tanggap na lámang sila nang tanggap ng kung ano ang ihapag ng media kahit na nililinlang na sila ng mga taga-telebisyon." Wari nga bang "layaw" ang "pagtalakay sa mga problemang panlipunan," tulad ng aking mga nabanggit na pagpipi. Ngunit "may mas interesanteng pananaw" ang dalawa na higit na magpapaliwanag sa kung papaanong hinubog ng mga pagbabago sa genre ang soap opera noong mga panahong iyon: "(N)andiyan pa rin ang mga soap opera dahil nandiyan pa rin ang mga problema sa lipunan; na kahit baluktot kadalasan ang pagbibigay-lunas ng soap opera sa karamdaman ng mundo, inuusisa ang sakít na ito upang matutuhan ang proseso ng paghilom." Nag-iwan sila ng tanong na magandang sagutin ngayon, sa liwanag ng Esperanza, ang sumunod na yugto ng pagganap ni Santos matapos ng Mara Clara: "Paglaya ba ang pakay ng soap opera?" (Flores at de la Paz 79). Ang ngalang "Esperanza" ay Espanyol para sa pag-asa, na kapag binulatlat pa ang kahulugan ay makapagbubungad sa mga sinonimong "kaasahan," "pananaw," "pangako," at "antisipasyon." Nawalay si Esperanza sa mga magulang at kapatid dahil sa isang aksidente sa bus, na matutuklasan niyang 
lumumpo sa ina, naging dahilan ng tuluyang paglayo ng ama, at nagpawatak-watak sa kanilang magkakapatid. Harangan man ng madrastang may mga tauhang debaril, ng politikong mapang-angkin at itinuring na anak ang isa niyang kapatid, at ng baliw na doktor na nagtago sa ina sa matagal na panahon, nanatili ang kaniyang esperanza na hindi matitibag ng mga balakid sa kanilang pagbuo ng pamilya, na isa pang institusyong pinahahalagahan din sa mga telenovela ng Amerika Latina. Nagtatagpo sa usaping ito ang telenovela at telenobela (at mahalagang linawin ang ganitong lingguwistikong kaibhan) bílang pagtatanghal ng mithiing mapagpalaya sa parehong antas ng kasarian at kasarian, at mistulang napalalaya rin ng telenobela ang sarili mula sa sarili nitong agon sa banyagang telenovela. Sa panahon ding ito ng Esperanza nagkaroon ng pambihirang "paglaya" si Santos sa kaniyang mga naunang papel ng kaapihan. Matatandaang bago ang soap operang tinalakay natin, lumabas na siya sa Gimik (pati na rin sa Gimik 2010: The Reunion), isang lingguhang seryeng pandrama na youth-oriented, kung saan itinalaga siyang maging si Diane na mula sa nakaririwasang pamilya at kapareha ang maalwan din sa buhay na si Ricky na ginampanan ni Rico Yan. Naglatag ng posibilidad sa mobilidad ang ganitong pagkakatalaga, bagay na tila ba "pagpapalaya" sa mga pagganap ni Santos. Sabay-sabay na paglaya ang nagaganap sa iba't ibang antas ng ating talakayan.

\section{MULANG SOAP OPERA PATUNGONG TELESERYE}

Natural na ganito ang mangyari sapagkat gumugulang si Santos (Larawan 3). Gumugulang ding kasabay niya ang soap opera na matapos sumilang-na-muli sa Rebolusyong 1986 ay makatatagpo ang telenovela mulang Amerika Latina. Sa pagtungtong ni Santos sa Sa Puso Ko, Iingatan Ka (sa direksiyon nina Jose Javier Reyes at Gilbert Perez), magkakaroon ng pag-iiba (divergence) ng mga dati at bagong anyo ng pagganap niya sa soap opera sapagkat sa yugtong ito'y higit nang malawak ang kaniyang danas sapagkat pinanday sa drama anthologies na pinagbidahan tulad ng GMA Telecine Specials (1993), Star Drama Theater (1996), at Judy Ann Drama Special (1999), maging sa taon-taon at matagumpay niyang pagganap sa mga pelikula. Ito rin ang unang soap opera ni Santos sa katawagang teleserye. Sa teleseryeng ito-na may higit nang matingkad na framing kaysa sa mga naunang drama ni Santos at kung saan unang makakatambal niya si Pascual-tatatalakayin ang kuwento ng isang babaeng naghahangad maging maalwan ang búhay habang tinutuklas ang nakaraan bílang isang anak sa pagkadalaga. Masalimuot ang salaysay ng kuwento sapagkat ang unang kinilalang madrasta pala ang tunay na ina, ang ugnayan sa naging asawa ay komplikado dahil sa nakaraan, at ang mga magulang ay may madidilim na lihim na tumigatig nang matuklasan. Binabása ko ang isang sinopsis ng teleseryeng ito ay hindi ko mapigilan ang sariling sabihin na dumaan nga ito marahil sa isang sandali ng mga pagkalito dala na rin ng pangyayaring ang ano mang pagharap sa kabaguhan ay nagdudulot ng desoryentasyon sa ano mang 
hinaharap nito. Ano ba ang nangyari sa teleseryeng ito, untag ko sa sarili. Bakâ maging kalabisan ang sabihing yugto ito ng pagganap ni Santos kung saan kinikilala pa ng anyo ng soap opera ang sarili nito bílang ganap nang nirebisa ng rebolusyon, ngunit nagtataya na rin ako, upang igiit na matapos ng Sa Puso Ko, nagkaroon nga ng higit na maliwanag na pagbabago sa mga pagganap ni Santos at pati na rin sa mga teleseryeng kaniyang kinatampukan. May iba sa gloss, kahit sa pag-iilaw sa kaniya, na nagliligtas sa kaniya sa higit na madilim na pagkakalarawan at pagtatanghal sa kaniyang mga naunang kadiliman. Samantala, makikitaan siya ng higit na tapang sa Basta't Kasama Kita (sa direksiyon nina J. L. Sineng at Trina Dayrit) katambal si Robin Padilla, kung saan siya ay abogadang kawani ng isang espesyal na unit ng National Bureau of Investigation. Sa ganang akin, ang papel niya rito ang talagang nagpakita ng gulang sa lahat, magpahanggang ngayon, dahil may kaibang anyo rin ang teleseryeng ito na bagaman umiinog sa proseso ng romantikong pagkahulog ng mga karakter nina Santos at Padilla sa isa't isa'y pinagagana ang kuwento ng mga imbestigasyong kasasangkutan nila. Eksperimental ang pamamaraan ng Basta't Kasama Kita bagaman tulad ng Sa Puso Ko ay unti-unti nang binabawasan ang tagal ng pagpapalabas, at may higit na paggulang ang pagkaka-frame kay Santos. Ang anyo ng teleserye sa pagkakataong ito ay hindi na tulad ng mga naunang soap opera na matatapos yata hanggang sa muling pagdating ng panginoon. Tumakbo ang Sa Puso Ko at Basta't Kasama Kita nang mahigit dalawang taon, bagay na masasabing tugon sa negosasyong temporal ng soap opera bílang teleserye. Upang matugunan ang gayong tiyakang pagtatapos, siniksik ng Basta't Kasama Kita ang mga kuwento, pinagdugtong-dugtong at masinsing binalangkas upang, wika nga ng mga New Critic, ay magkaroon ng organikong kaisahan at isahang epekto. Natatangi rin ang serye sapagkat tinunghan nito ang merkado ni Padilla, ang merkado ng mga kalalakihang mahilig sa aksiyon, habulan, at barilan - isang malinaw na pagtaliwas sa nakamihasnang operasyon ng soap opera at maging ng teleserye sa panahong ito. Ipinagmamalaki rin ng teleseryeng ito ang pagtatampok sa isang "live" na pagtatapos, kuntodo sa mga pailaw at palakpakan ng tao sa gitna ng Luneta. Higit na magiging katangi-tangi ang yugtong ito ng "eksperimentasyon" at pagbabago sa pagsapit ni Santos sa una niyang fantaserye, ang Krystala (ang fantaserye, o seryeng nakatuon sa genreng fantasy, ay unang ginawa ni Barretto sa Marina, kung saan siya gumanap na isang sirena). Sa kaniyang Facebook page na "Filipino Fantastic," inilarawan ni Edgar C. Samar ang fantaseryeng ito bílang "kagila-gilalas na naratibo ng bayaning babae, ng babaeng tagapagligtas ng bayan sa kadiliman" at "unang gumamit ng kategoryang superserye" batay na rin sa matinding kapit nito sa "naratibo ni Narda/Darna" (isa pang bagong katawagan sa teleserye!). Bagaman may pinag-ugatan nang tradisyon ng babaeng superhero, matapang na tinuklas pa-muli ng Krystala, maging ng pagganap ni Santos dito, ang ilan pang posibilidad ng apropriasyon ng katutubo sa kabayanihang tunay mang lalang ng Hollywood at banyagang kulturang popular ay nakapag-ugat na rin sa lokal na kamalayan, lalo pa't binibigkas sa konteksto ng teleseryeng kinakitaan na 
ng tendensiya ng pagkasari-sari dahil patuloy na sumasagap ng kabaguhang dala ng patuloy na pakikipag-ugnayan ng brodkasting sa Filipinas sa malawak na daigdig. Isa ring animo'y inog-pa-muli ang teleseryeng ito sa pagganap ni Santos, na unang kikilalanin sa isang pagganap na may tagpuang masukal - ang gubat. Sa gubat magkakamalay ang karakter ni Santos na si Tala, isang batang gubat tulad ni Ula, at matutuklasan ang kaniyang kapangyarihan bílang piniling nilalang na kumatawan sa kapangyarihan ng kristal. Sa teleserye ring ito, muling gaganap na nanay niya si Susan Africa na gumanap din sa gayong papel sa Mara Clara. Ang makahulugang pagbabalik sa mga unang lunan ng pagganap ay isang tanda ng higit na pagkaunawa sa mga puwang ng anyong nagbabago man ay patuloy na ginagalawan.

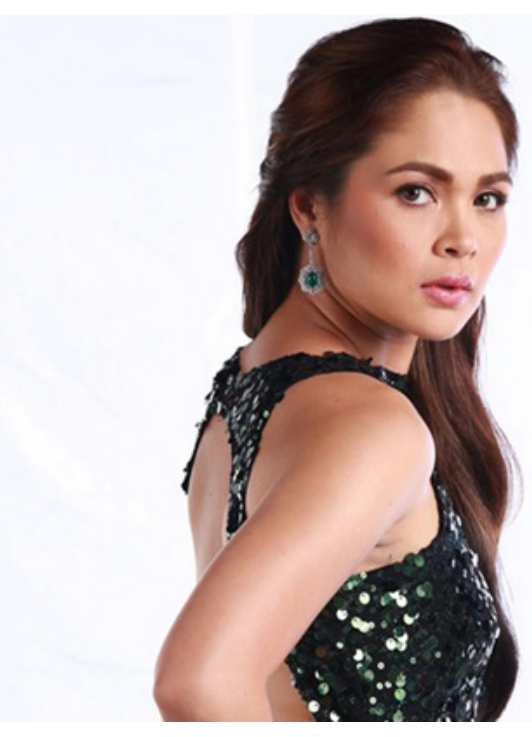

Larawan 4. Si Judy Ann Santos sa Huwag Ka Lang Mawawala (Dreamscape Entertainment TV \& ABS-CBN, 2013).

Tatabo ng maraming pagkilala para kay Santos ang Basta't Kasama Kita at Krystala, at kung batayan nga ang mga pagkilala, tulad ng makikita sa talâang inilaan para sa kaniya ng Film Academy of the Philippines, mukhang malayò na nga ang kaniyang narating. Ngunit higit pa siyang itutulak ng mga kabaguhan sa teleserye sa iba pang pagganap tulad ng gagawin niya sa Sa Píling Mo (sa direksiyon nina J. L. Sineneng, R Quintos, at T. Dayrit). Sa kuwentong ito, na muli nilang pagbibidahan ni Pascual, dalawang bagay na animo'y malayòng magtagpo ang tinatalakay: ang desabilidad at ang pusikit na búhay krimen. Magsing-irog ang mga karakter nilang sina Jennifer at Adrian. Bulag si Adrian at mimithiin ni Jennifer na maipaopera ang kaniyang mahal. Sa mithiing ito, mapipilitan si Jennifer na pasukin ang isang sindikato upang matustusan ang pagpapagamot ng kasintahan. 
Magbabago rin siya ng katauhan upang ganap na mapasok ang sindikatong nabanggit. Dahil sa mangyayaring pagkakakulong, magkakahiwalay ang dalawa, upang magtagpo sa kalagitnaan ng istorya nang hindi magkakilala, at may isa pang babaeng nakapagitan. Ang pagtatagpo't pagpapaliwanag ng dahilan ng pagkawala ng babae ang magiging ubod ng tunggalian at pagpapatuloy ng kuwento, na sa huli'y magwawakas sa muling pagsasama. Nagmumula si Santos sa panig ng batas at katwiran sa mga teleseryeng Basta't Kasama Kita at Krystala, at isang kakatwang pihit ang eksperimento sa pagdadala sa kaniya sa "dilim" ng krimen na madalas kahindikan ng maraming artistang may "pinangangalagaang" imahen. Dito pa lámang ay mapatutunayan nang hindi talaga maikakahon ang aktres sa kaniyang mga "payak" na pinagmulan. Mapaglaro para sa akin ang pakana ng pagiiba ng katauhan sapagkat sa gawaing ito makikita ang pagsusuot ng maskara ng aktres, sa láyong subukin ang mga katauhang madalas na itinatakda para sa ibang tao. Gayundin sa palagay ko ang nangyayari sa mga teleserye bílang isang anyo na kailangang paghimagsikan ang sariling mga padron upang maging kakaiba bagaman may matalik na pagsasaalang-alang sa mga ito. Mahalaga ang imahen ng bida sapagkat napakanipis, talagang kaynipis ng pagitan ng kanilang persona at ng katauhan para sa publiko. Ang ganitong pihit ng Sa Piling Mo ay mistulang pagpapadala kay Santos sa piling ng dilim upang doon ay maghunos, bagay na literal na nangyari sang-ayon sa naging banghay ng kuwento. Sa teleseryeng ito, pinuri ang kaniyang praktikal na kagawian, tinangkilik ng mga tao't nagtulak pa nga sa isang nangungunang kompanyang pantelekomunikasyon na bayaran ang huli nitong episodyo upang umeyre nang walang patalastas. Sa unang pansin, ang interbensiyon ng negosyo sa kasong ito ay maaaring balingan bílang isang komersiyal na pagtupad sa malaon nang inaasahang pagsabay ng pamumuhunan sa industriya ng soap opera. Ngunit isa rin itong pagtugon sa matinding mithi ng manonood na makapanood ng teleserye nang hindi naaantala ng langkay-langkay na patalastas (na madalas ay mas marami pa ngang minutong kinokonsumo kaysa sa mga teleserye). Ang mga ganito'y bihirang mangyari ngunit dahil marahil sa bagong anyo ng teleserye at sa mismong pagganap ni Santos, makikitang nakikipagnegosasyon na rin ang negosyo upang maibalik mismo sa sentro ang desentralisadong texto, ang ispektakulong nilulunod sa patalastas. Ngunit hindi ito ganap na totoo. Sa malaon, matututuhan din ng negosyo na linlangin ang madla sa animo'y pagbabalik nga sa sentro ng salaysay; nakapaloob pa rin sa ganoong "kabutihang-loob" ang banayad na pagsisilid ng mismong mga produkto sa loob ng istorya-isang gawaing noon pa man ay tinutupad na ng mga soap opera at muli lámang nabalikan sa bago nitong anyo ng teleserye. Ganito ang kaso ng Ysabella (sa direksiyon ni J. L. Sineneng, R. Quintos, at D. Cuaresma), na naglalaman ng kuwento ng isang chef na nangarap magtagumpay sa pamamagitan ng isang resepi ng piniritong manok na minana niya sa kaniyang nasirang ina. Ang piniritong manok na iyon ay inilako ng network sa isang chain ng restoran na ang espesiyalidad ay Bacolod Chicken Inasal. Uminog ang kuwento sa malihim at branded na manok, at siyang puno't dulo ng tunggalian 
ng kuwento. Maraming pagkakataon nang ginawa ito sa telebisyon, ngunit sa ganang akin, ito ang isa sa unang pagkakataon na nagkaroon ng direktang interbensiyon ang advertising para sa kuwento ng teleserye. Nagbabago nga ang anyo ng soap opera sa pagiging teleserye subalit hindi pa rin nito naigpawan ang nabanggit nang "economic imperative" sapagkat sa huli mananatili pa rin itong pinatatakbo ng suporta ng advertising bukod pa sa regular na riserts at pagpulso sa merkado. Sa pagkakataong nabanggit, ang bagong anyo ng soap opera bílang teleserye ay naging daan pa nga upang maging ispektakulo ang isang produktong inilalako. Nakasunod ang negosyo sa bagong anyo ng soap opera.

Bagaman ganito-at talaga namang hindi maiiwasan-nakapagpasinaya pa rin ang teleserye, sa pamamagitan ng pagganap ni Santos, ng mga usaping buháy sa konteksto ng maraming manonood. Interesanteng banggitin na ang naging tunguhin ng mga pagganap niya mulang Basta't Kasama Kita hanggang sa Ysabella ay ang pagbaling sa mga propesyong nagbibigay ng higit na kapangyarihan at mobilidad para sa mga babaeng karakter na ginagampanan. Ang pagkalulong ni Santos sa pagluluto sa tunay na búhay (at pagkakamit ng sertipiko ng pagtatapos sa isang paaralang culinary) ay naging hudyat sa pagsusuot ng chef's hat sa teleserye, at pagsasalaysay gamit ang pagkain, kasabay ng pagkauso ng mga paaralan at kurso sa culinary arts. Ang pagganap naman sa papel ng isang abogadang imbestigador ay masasabing isang paraan ng pagpapasok sa isang babaeng karakter sa maskulino at patriyarkal na daigdig ng pulisya at paghahanap ng hustisya (kasama pa si Padilla!), bagay na tila sinasalamin din ng matapang niyang pag-eendorso kay Jamby Madrigal, isang negosyante't tagapagbandila ng mga isyung pangkababaihan na naipanalo niya nang mga panahong iyon ng teleserye, ngunit pinagsisihan ang kaugnayan sa kalaunan dahil sa isang alingasngas (Rimban 44-53). Ang teleserye niya bago ang pinakahuling Huwag Ka Lang Mawawala, ang Habang May Buhay, ay tumalakay naman sa búhay ng mga nars. Hindi masasabing ganap ang pagtalakay na medikal ng nasabing teleserye sa kuwento ng mga tauhan; tandaang ang bida ay si Santos na pinanonood dahil sa kaniyang husay sa melodrama. Ngunit sumasabay ang pagpapalabas dito sa pagtaas ng bílang ng mga kumukuha ng kursong nursing at ng maraming isyung nagsasangkot sa industriyang ito na may malaong matinding halina para sa mga nagnanais mangibang-bansa. Panahon din iyon ng masasabing "crackdown" sa mga patakbuhing paaralan ng nursing. Sa ganang akin, ang pagpapalabas ng Habang May Buhay ay pagsiyasat ng pagganap ni Santos sa isang malaganap na mithiin ng mobilidad, at kinakasangkapan lámang nito ang industriya ng pagnanars bílang kontemporaneong mukha ng láyong pagangat. Kahit anong propesyon naman ay maaaring piliin para sa proyektong ito. Sa kabila nito, mapahahalagahan ang isang "inobasyon" na matatawag ng teleserye sa mismong praktika ni Santos: ang pagkasangkapan sa materyales ng panahon, isang pagtutok sa masasabing mahahalagang karanasan ng kasalukuyang minulan ng teleserye. May kakayahan at panahon ang teleserye na gawin ito dahil na rin sa 
seryalidad nito; hinihingi ring maging napapanahon ang dramatisasyon nito upang higit na maging maugnayin lalo na sa mga isyung panlipunan. Larawan ang kuwento ng nars na si Jane ng maraming pagpupunyagi ng karaniwang Filipino. Sa mga panahong iyon - at magpahanggang ngayon naman - ang opsiyong diasporiko ay humahalina sa madla. Sa "sariling" tradisyon ng soap opera sa Filipinas, sa anyo nito bílang teleserye, nakakasangkapan kahit papaano ang modang dramatiko upang isadula ang mga pangyayari ng minulang kasalukyan. Kaya maaari tuloy sagutin ngayon ang iniwang tanong nina Flores at de la Paz: Paglaya ba ang pakay ng soap opera? Sa pinakahuling pagtalakay na ito, na nararapat lámang iugnay sa nauna nang diskusyon sa pinakahuling teleseryeng ginawa ni Santos kamakailan, ang Huwag Ka Lang Mawawala, makikitang buháy na mithiin ng teleserye, sa korpus ng pagganap ni Santos, ang diwaing mapagpalaya, sa aspektong ekonomiko man, pati na rin sa mga pagtataya ng lipunang patriyarkal. Nagiging mahusay na behikulo ang teleserye para sa mga adhikaing ito lalo pa't binabalikan din ng papel ang "rebolusyonaryo" nitong minulan, at bílang lohika ng makasaysayang rebolusyong muling nagpalaya sa industriya ng brodkasting sa bansa. "Politikal" ang layon ni Santos sa Huwag Ka Lang Mawawala: ang talakayin ang karahasan laban sa mga kababaihan, siyang rurok marahil ng patuloy na pagbabalon ng soap opera sa sosyorealistang tradisyon ng panitikan, na sa ganang akin ay higit na nakatutulong sa paghubog sa mga teleserye sa kasalukuyan na may katapangang talakayin, halimbawa, ang korupsiyon sa gobyerno, maruming halalan, at inmoralidad ng kalabisan. At sinamahan pa ang teleserye ng mga testamento ng kababaihang manonood na nagpapatunay kung papaanong nakatutulong ang panonood ng teleserye sa pagbubukás ng kamalayan ng lipunan hinggil sa pandarahas sa babae. May iba mang palagay si Torre na nauna na nating sinipi't tinitigan, hindi mapasusubalian ang naging pasya ng teleserye, sa pagganap ni Santos, na punahin ang totoo namang nangyayari ngunit hindi pinaguusapan. Bilang nars na si Jane at mag-aasin na si Anessa, pinapasok ni Santos ang isang diskursong politikal na lagpas sa hanggahan ng pagkakatalaga sa kaniya sa mga nakaraang pagganap at ng teleseryeng lumilikha ng mga bagong hulmahan sa ano mang pagsasalaysay.

\section{PAGLAGPAS SA MGA HANGGAHAN NG TELESERYE}

Natunghayan sa papel na ito ang isang matalik na pagtugaygay sa naging takbo ng karera ni Santos habang naghahanap ng puwang sa daigdig ng telebisyon at gumagawa ng mga soap opera. Tinuklas din ng papel ang ugnayan ng kaniyang mga pagganap sa naging pag-unlad ng soap opera sa Filipinas. Ang pangunahing mithi ng papel na ito ay alamin kung papaanong naigpawan niya ang ano mang naunang pagtataya sa kaniya bílang isang "ordinaryong" aktres na mistulang mananatili na lámang sa sulok na takda, sa soap opera at sa karugtong na daigdig ng pelikula. Siyempre, may iba ring naging tagumpay si Santos sa pinilikang tabing na hindi 
na sákop ng pag-aaral na ito. Ngunit nais kong tapusin at lagumin ang paggigiit ng henyo ng pagganap ni Santos, at ng kaakibat na kasaysayan ng pag-unlad ng soap opera-na ngayon ay tinatawag nang teleserye-sa pamamagitan ng isang pelikulang masasabing tunay na naging puwang at tanghalan ng kaniyang paggigiit na may sarili siyang bait at galíng na nahasa sa kaniyang matagal na pamamalagi sa soap opera. Pelikula itong hindi pinatakbo ng makinarya ng malalaking studio-pelikula itong siya mismo ang namuhunan. Pelikula rin itong kumatawan sa Filipinas sa Oscars Best Foreign Language Category ng Academy Awards ng Estados Unidos (Dimaculangan n.p.). Ang pelikulang ito, ang Ploning (sa direksiyon ni Dante Nico Garcia), ay ipinagmamalaki ni Santos dahil "nakakaiyak" kahit "walang sampalan o sigawan" (Gonzales n.p.), mga pangunahing halagahang melodramatiko sa soap opera sa Filipinas, bukod sa malungkuting salamisim (dahil sa dusa), lantarang pangangaral, at komikong imahinasyon (Larawan 4). Sinipi na natin ang paglalarawang ito sa mga naunang seksiyon upang igiit ang kabatiran ni Santos sa anyong telebiswal na pinamumuhatan niya sa kabila ng tila walang muwang na himig ng pagkakalarawan. Binabalikan ko ito ngayon upang basahing muli at suriin bílang isang animo'y panunukat ng sariling narating, ng láyo ng kaniyang narating matapos ng mahabang panahon sa soap opera at pelikula. Sa Ploning, kung saan siya gumanap bílang isang misteryosong babae na naging paksain ng paghanga at taká sa isla ng Cuyo, Palawan, nagpakita siya ng kakaibang pagganap na testamento ng paglabas sa mga paghahanggahan ng soap opera na siya mismo ay maláy na kasangkot, at sa paunang teoretikong balangkas ay ipinagpalagay na "pundadora." Sa pagbuhay niya sa karakter ng matimpiing babae na naghintay, umasa, nasaktan, ngunit nagpatuloy mabuhay sa gitna ng kapayakan at katahimikan ng isang baryong naliligid ng dagat, nakalikha si Santos ng isang matulaing pagganap na lagpas sa hanggahan at pagdisiplina ng soap opera-at sa isang banda'y tumutuligsa pa nga sa mga modang natutuhan niya rito. Mahalaga ang Ploning sa karera ni Santos sapagkat dito niya ibinukod ang sarili mula sa matagal-tagal na pagbabad sa pelikula at melodrama ng soap opera, na sa mga darating ngang panahon ay naging teleserye. Sa pelikula, gagawin ni Santos ang mga bagay na hindi niya kadalasang ginagawa: kaluluwa niya ang katahimikan upang katawanin ang mahiwagang babae na minamahal ng nakapaligid sa kaniya at kinamamanghaan ng tanging tagapagsalaysay ng kaniyang kuwento. Sa unang malas, tama ang kaibigang karakter ni Santos, ang nars na si Celeste (Mylene Dizon) sa pagsasabing isa siyang mahinang babae-tipikal sa mga karakter niya sa mga teleserye kung saan siya inaapi. Subalit ang "hina" na ito ay mapanlansi, sapagkat nababalot ng balintuna. Papaanong humaharap ang babaeng mala-Penelope na ito sa isang "paghihintay" (sa isang mahal na patay na pala) na wari'y pangarap na lámang? Papaanong pinaniniwala ng babaeng ito ang kaniyang sarili na maganda pa nga ang daigdig? Panatag, laging panatag si Santos sa pelikula, liban na lámang sa tanging sandali ng kaniyang pagluha - nang ihabilin ng amang mamamatay na isuot niya ang puting bestida sa libing. Hindi teleserye ang pelikula, "indie" nga kung ituring, ngunit sinakop ito nang maluwat ng nag-iisang 
reyna ng teleserye sa pamamagitan ng paglalarawan sa danas ng kasawian bílang lagi't laging sandali ng pagninilay at pagbabalik-tanaw. Wala ngang sampalang naganap dito. Piling-pili ang mga binibitiwang salita. Kasangkapan ang matulaing biswalidad, mahusay na karekterisasyon, at mapahiwatig na paglalahad, naitanghal sa pelikula si Santos bílang isang "nakarating na nga" sa nibel ng makasining na pagsasatao. Lahat ng kaniyang pihit ay wasto, at napapatirapa siya sa mga tamang sandali (masdan na lámang ang pagtanggap sa balita ng pagkawala ng itinuring na anak-anakan). Piece de resistance ni Santos ang Ploning matapos ng malaong pag-aaral sa eskuwela ng dramang pantelebisyon. Nagtatag ng sarili si Santos sa pagtawag sa isang katutubong awiting Cuyonon (at paglikha mula rito ng isang di malilimot na karakter), pag-awit sa kuwento ng lupain at karagatang kaylayo, at pagpaparinig kahit papaano sa isang wikang halos limót. Ginawa niyang drama ng lokasyon ang kaniyang pagsasatao. Kaya matalinghaga rito ang pagiging "indie" niya at ng kaniyang pelikula, sa panahong nakatindig pa rin ang kaniyang karera sa komersiyal na network system. Kinaya niyang magsolo, at nakaalpas siya sa hanggahan ng kaniyang nakamihasnang pag-arte.

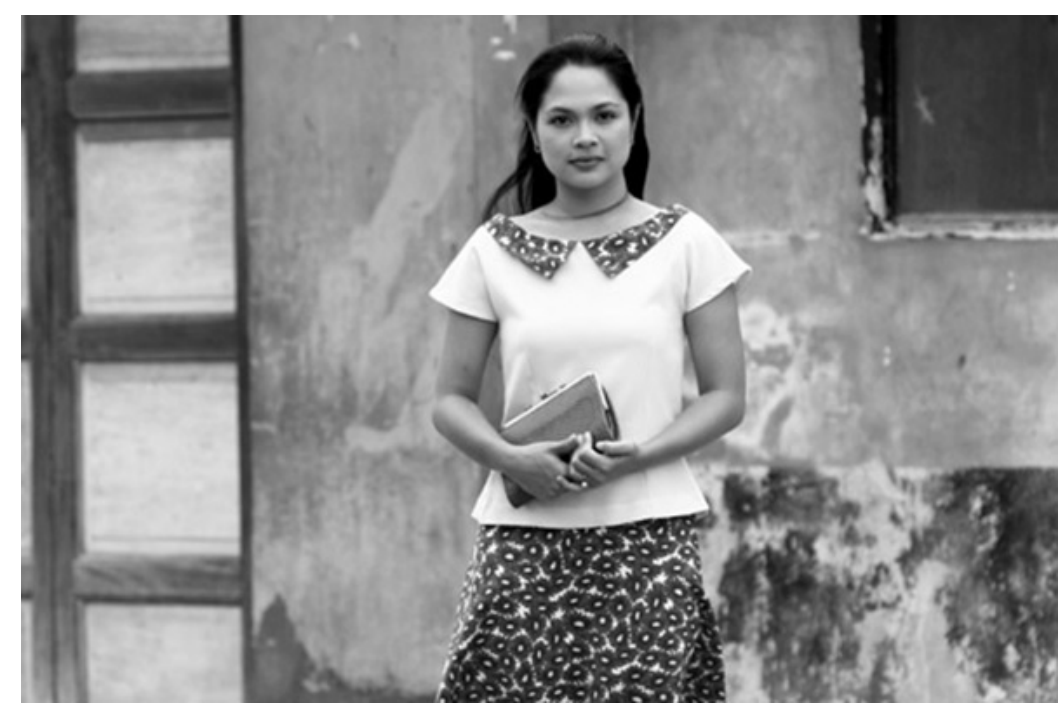

Larawan 4. Si Judy Ann Santos sa Ploning (dir. Dante Nico Garcia, Panoramanila Pictures, 2008).

Mistula ring nakipaglaro si Santos sa sarili niyang pagkakatalaga sa puwang ng ordinaryo dulot na rin ng matulaing pagganap sa ordinaryong búhay ni Ploning, na tila may nakapagsasariling tagpuan at kasaysayan. Binanggit nang naging mapaglaro si Santos sa kaniyang mga pagganap, at ganitong kakayahan din sa aking palagay ang nagdulot sa kaniya na "makatakas" sumandali sa espasyo ng soap opera 
upang tunghan ang kaabang-abang na espasyo ng independent film production, kung saan higit siyang may kontrol sa materyales at may pagkakataong gumanap sa papel na aniya'y higit na maigting at mapaglimi. Interesanteng tunghan ang Ploning, kaugnay ng lawas ng mga soap opera na pinagbidahan ni Santos, sapagkat wari'y paulit-ulit ang pagbabalik-tingin ni Santos sa telebiswal na anyo upang ilarawan ang simpleng kasiyahan sa tagumpay ng produksiyong umani man ng pamununa mula sa mga kritiko'y pinuri naman ng ilan, tulad ng kolumnistang si Katrina Stuart Santiago, na nagsabing "this film is anything but shallow, and is nowhere close to being simple - or simplistic" (n.p.). May pagmumultong nagaganap sa ganang akin, minumulto yata si Santos ng "aura ng ordinaryo" na unang napansin sa kaniya ni Tolentino, at kahit ang direktor ng Ploning na si Garcia ay walang tákot sa pagsasabing "mababaw" lámang ang pelikula at "hindi pang-intelektwal." Ngunit sumasang-ayon ako sa pagtatanggol ni Santiago sa pelikula, lalo pa't totoo namang isa itong tanghalan ng pagtakas ni Santos sa "sumpa" ng iginawad na "kapayakan." Sa hakang kasaysayang ito itinanghal ang pag-igpaw ni Santos sa pagkakatalaga bílang ordinaryo: ang lawas ng pagganap niya'y ikinurus sa lawas ng paghuhunos ng soap opera sa Filipinas, na naging teleserye. Kaniyang-kaniya ito bílang genre, sa pagmalas natin sa texto ng kaniyang mga pagganap, at sa pagkakahubog nito/sa mga ito ng genre na humarap sa pagbabago matapos ang pagbabalik ng demokratisadong telebisyon. Ngunit hindi matatapos ang pagsusuri hangga't hindi natititigan ang isa pang masasabing talagang tinatakasang anino ni Santos, na sa kritikang Tolentino ay malinaw ding naitanghal: ang kaniyang ugnayan kay Aunor. Mauulinig ang ganitong "pakikipagtagisan," lalo't kung babalingan ang sinabing ito ni Santos mismo, sa panayam ding sinipi hinggil sa Ploning, kung saan patuloy niyang ipinagmamalaki ang uri ng pagganap na kaniyang natupad: "Oo, yung mata lang yung magsasalita. Kung makikinig silang (manonood) mabuti, at magbabasa silang mabuti sa mga dialogues namin, mararamdaman nila nang todotodo yung bawat eksenang makikita nila" (Gonzales). Kakatwa ang pagtukoy sa pagganap na gamit lámang ang pagtingin, bagay na madalas iugnay sa matimping pamamaraan ni Aunor. Hindi nga ba sinasabi ng maraming tagahanga na sa mata pa lámang, umaarte na si Nora? Ang láyong kamtin din ang masasabing sandali ng mga mata, ang sandali ng báling na Aunor (Aunorian gaze, kung mamarapatin) ay hinangad din ni Santos sa kaniyang proyektong ito na monumento ng kaniyang kadalubhasaan sa soap opera, at sa teleserye, kung saan siya nagrereyna. Ang binitiwang pahayag na ito ay madaling hatulan na paggigiit lámang ng patuloy na pagbatá ni Santos sa bagabag ng impluwensiya ni Aunor na may sarili nang lawas ng pananagumpay sa pagiging "ordinaryo" sa kaniyang panahon. Ngunit magtatangka akong magmunakala sa isang bagay na maaaring tuligsain ng ibang tagahanga ng "Superstar." Ang aking munakala, matagumpay si Santos sa pagbatá sa kaniyang "pakikitunggalian" sa kaniyang "magulang" na si Aunor (pahiram, Harold Bloom) kung susuriin ang sanda-sandaling pagpasok ng iginagalang na aktres sa pagganap sa mga soap opera. Pahapyaw ko lámang itong gagawin ngayon. 
Kung tatag ang pag-uusapan, hindi naman natin pagtatalunan pa ang tagumpay ni Santos sa soap opera. Kinalakhan niya ito't nakita nga nating inangkop bílang kaniya (sa gayong inangkop din ng anyo ang kaniyang mga pagganap). Noong 2003, halos magkasunod ang pagpapalabas ng mga teleserye nilang Basta't Kasama Kita at Bituin (sa direksiyon ni T. Dayrit at John D. Lazatin), ang kauna-unahang teleserye ni Aunor, kung saan siya gumanap na ina ng dalawang anak na magiging magkaribal bílang mga papausbong na mang-aawit. Para sa akin, nangangailangan ang isang Aunor ng mas malawak na puwang kung saan maitatanghal niya ang kaniyang matimping pagganap. Hindi iyon nangyari sa Bituin. Ang teleserye sa aking palagay ay walang panahon upang pagnilayan ang kaniyang tatak na galíng, na panday ng matagal na pamamalagi sa pelikula. Nabanggit nang kilalá si Aunor sa kaniyang mga mata - at sa pangkalahatan, sa masasabing mapahiwatig na mga sinekdoke ng kaniyang kabuuang pagganap - at ang Butuin, sa pangkabuuan ay kinailangang patakbuhin pa rin ng banghay, siyang ubod ng genre, upang mapanatili ang pagtangkilik ng manonood. Naging karaniwan si Aunor, na sa aking palagay ay inhustisya lalo pa't laging hihingi ng matalik na pagtitig ang bawat niyang pagganap. Mangyayari rin ito, sa aking palagay sa kaniyang ikalawang subok sa teleserye, ang Sa Ngalan ng Ina, kung saan gagampanan naman niya ang papel ng isang politikong matriyarka. Ang pagganap niya rito'y hindi gaanong pumukaw sa parehong dahilan: ang mabilisang paglalahad ng teleserye'y sumusupil sa mga pagkakataong maaari sanang higit na malasap ang matulaing pagganap ni Aunor. Sa telebisyon, ang subók na genre ni Aunor ay ang pagtatanghal, ang pag-awit sa entablado bílang pangunahing ispektakulo. Hindi ko sasabihing ganap na nakalulungkot ang ganitong kaso, sapagkat sa ganitong dahilan napananagumpayan ni Santos ang Elektra kompleks kay Aunor. Hindi genre ni Aunor ang teleserye, tiyak iyon, hindi pa niya kabesado ang rules of assemblage, ngunit baká nga kailangan lámang siyang hanapan ng magandang materyales at pagkakataon. Magiging matagumpay kaya ang GMA 7 dito, lalo't sinimulan na nilang ipasok ang karakter ni Aunor sa teleseryeng "relihiyoso" ni Dingdong Dantes na Pari Koy? Dapat na panoorin at abangan. Sa huli, sa pagitan ng mga ikon, makikitang nangingibabaw ang "anak" kaysa sa "ina," at sa natunghayan nating mga nagkukrus na kasaysayan - at sa pagsasatexto ng mga ito-naisasawika ang mga kawili-wiling paghahambing na tiyak namang nagpapahiwatig ng maraming bagay hinggil sa kontemporaneong kulturang popular, patuloy man itong ituring na lubhang karaniwan. 


\section{Mga Binanggit na Akda}

Allen, Robert. Speaking of Soap Operas. Chapel Hill: U of North Carolina P, 1985. Aklat.

Ana Liza. GMA 7. Lungsod Quezon, 1980-86. Telebisyon.

Barthes, Roland. Image, Music, Text. London: Fortuna Press, 1977. Aklat.

_- - Sade Fourier Loyola. Los Angeles: U of California P, 1989. Aklat.

Basta't Kasama Kita. ABS-CBN 2. Lungsod Quezon, 2003-04. Telebisyon.

Bituin. ABS-CBN 2. Lungsod Quezon, 2002-03. Telebisyon.

Creeber, Glenn, ed. "Studying Soap Opera." The Television Genre Book. $2^{\text {nd }}$ Ed. London: British Film Institute, 2008. 60-62. Aklat.

D’Acci, Julie. "Gender, Representation, and Television." Television Studies. Ed. Toby Miller. London: British Film Institute, 2008. 91-94. Aklat.

Dimaculangan, Jocelyn. "Ploning is Philippine entry to 2009 Oscar Awards' Best Foreign Language Film Category." Philippine Entertainment Portal, 1 Sept. 2008. Web. 5 Apr. 2015 .

Esperanza. ABS-CBN 2. Lungsod Quezon, 1997-99. Telebisyon.

“Fans, Academe Launch Initiative to Declare Nora Aunor 'People's' National Artist." Gmanetwork.com, 2 July 2014. Web. 29 Aug. 2015.

Filipino Fantastic. "10 Most Fantastic ABS-CBN Teleseryes." Facebook, 20 Mar. 2014. Web. 24. Apr. 2015.

Fernandez, Doreen G. Palabas: Essays on Philippine Theater History. Lungsod Quezon: Ateneo de Manila UP, 1996. Aklat.

Fiske, John. "Cultural Studies and the Culture of Everyday Life." Cultural Studies. Eds. Lawrence Grossberg, Cary Nelson, and Paula Treichler. New York: Routledge, Taylor \& Francis, 1992. 154-73. Aklat.

Flordeluna. RPN 9. Lungsod Quezon, 1979-84. Telebisyon. 
Flores, Patrick D., at Cecilia Sta. Maria de la Paz. Sining at Lipunan. Lungsod Quezon: Sentro ng Wikang Filipino at U ng Pilipinas Diliman, 20oo. Aklat.

412th Daytime Entertainment 2013-2014 Emmy Awards General Rules and Procedures. New York: National Academy of Television Arts and Sciences, 2013. Aklat.

Garcia, Dante Nico, dir. Ploning. Gumanap Judy Ann Santos, Cedric Amit, Mylene Dizon, Bodjong Fernandez, Gina Pareño, Eugene Domingo, Tessie Tomas. Panoramanila, 2008. DVD.

Gimik. ABS-CBN 2. Lungsod Quezon, 1996. Telebisyon.

Gimik 2010: The Reunion. ABS-CBN 2. Lungsod Quezon, 2010. Telebisyon.

Gonzales, Rommel. "Judy Ann Santos Says She Is Like Ploning in So Many Ways." Philippine Entertainment Portal, 6 Apr. 2008. Web. 18 Apr. 2015.

Habang May Buhay. ABS-CBN 2. Lungsod Quezon, 2010. Telebisyon.

Huwag Ka Lang Mawawala. ABS-CBN 2. Lungsod Quezon, 2013. Telebisyon.

Jimeno, Jaileen F., and Annie Ruth Sabangan. "Showbiz Endorsers Rule in Philippine Elections.” Philippine Center for Investigative Journalism, 7 May 2010. Web. 2 Mar. 2015 .

"Judy Ann Santos." Filmacademyphil.org. Film Academy of the Philippines website, 2008. Web. 13 Aug. 2015.

"Judy Ann Santos's Road to Royalty on Jeepney TV." Philstar.com, 13 June 2013. Web. 31 Mar. 2015.

"Judy Ann Santos's 'Royal Journey' Retraced in TV Special." ABS-CBN News.com, 12 June 2013. Web. 25 Apr. 2015.

Kaming Mga Ulila. GMA 7. Lungsod Quezon. 1986. Telebisyon.

Krystala. ABS-CBN 2. Lungsod Quezon, 2004-05. Telebisyon.

Marimar. Univision Televisa. Mexico, 1994. Telebisyon.

Mitchell, WJT. Iconology: Image, Text, Ideology. Illinois: U of Chicago P, 1986. Aklat. 
May Bukas Pa. ABS-CBN 2. Lungsod Quezon, 2009-10. Telebisyon.

Mara Clara. ABS-CBN 2. Lungsod Quezon, 1992-97. Telebisyon.

Mula sa Puso. ABS-CBN 2. Lungsod Quezon, 1997-99. Telebisyon.

“The Nora Aunor Affair." Editorial. The Manila Times, 23 June 2014. Web. 9 Apr. 2015.

100 Days to Heaven. ABS-CBN 2. Lungsod Quezon, 2011. Telebisyon.

Rabinow, Paul, ed. The Foucault Reader. New York: Pantheon Books, 1984. Aklat.

Reyes, Soledad R., ed. Reading Popular Culture. Lungsod Quezon: Office of Research and Publications at Ateneo de Manila U, 2002. Aklat.

Rimban, Luz. "The Empire Strikes Back." From Loren to Marimar: The Philippine Media in the 199os. Ed. Sheila Coronel. Quezon City: Philippine Center for Investigative Journalism, 1999. 44-53. Aklat.

Sa Ngalan ng Ina. TV5. Lungsod Quezon, 2011. Telebisyon.

Sa Puso Ko, Iingatan Ka. ABS-CBN 2. Lungsod Quezon, 2001-03. Telebisyon.

Sa Piling Mo. ABS-CBN 2. Lungsod Quezon, 2006. Telebisyon.

Sanchez, Louie Jon A. “The Real Soap Siren.” Rogue (December 2014): 167. Babásahín.

Santiago, Katrina Stuart. "In Defense of Ploning." Radikalchick.com, May 17, 2008. Web. August 3, 2015.

$67^{\text {th }}$ Primetime Emmy Awards 2014-2015 Rules and Procedures. Hollywood: Academy of Television Arts \& Sciences, 2014. Aklat.

Tolentino, Rolando B. "Judy Ann Santos at ang Aura ng Ordinaryo." Richard Gomez at ang Mito ng Pagkalalake, Sharon Cuneta at ang Perpetwal na Birhen, at Iba Pang Sanaysay Ukol Bida sa Pelikula Bilang Kultural na Texto. Lungsod Pasig: Anvil, 2000. 103-110. Aklat.

Torre, Nestor U. “Instructive Lessons from Judy Ann's Drama Series." Philippine Daily Inquirer, 20 Sept. 2013. Web. 5 Apr. 2015. 
Tadiar, Neferti Xina M. Fantasy Production: Sexual Economies and Other Philippine Consequences for the New World Order. Hong Kong: Hong Kong UP, 2004. Aklat.

Ula, Ang Batang Gubat. IBC 13. Lungsod Quezon, 1988-1990. Telebisyon.

"Why Judy Ann's New Teleserye Was Put on Hold." ABS-CBN News.com, 17 June 2015. Web. 7 Apr. 2015.

Wimsatt, W. K. The Verbal Icon: Studies in the Meaning of Poetry. Louisville: U of Kentucky P, 1954. Aklat.

Ysabella. ABS-CBN 2. Lungsod Quezon, 2007-08. Telebisyon. 